\title{
Trust Issues and Engaged Buddhism: The Triggers for Skillful Managerial Approaches
}

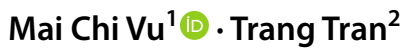

Received: 6 January 2018 / Accepted: 27 August 2019 / Published online: 4 September 2019

(c) The Author(s) 2019

\begin{abstract}
As a transitional economy, Vietnam has undergone tremendous changes over recent decades within a 'fusion' context that blends both traditional and modern values from its complex history. However, few studies have explored how contemporary issues in the context of Vietnam have brought both obstacles and skillful initiatives to managerial approaches to doing business. We draw on the concepts of social trust and institutional theory to explore how informal institutions such as religious forces can contribute to the development of individual trust and whether individuals are willing to extend trust beyond familial networks. We contribute to the notion of a moral conception of trust by exploring how Buddhism in particular has initiated distinctive managerial approaches in the context of Vietnam, in response to dilemmas of social trust. Our findings highlight that as an informal institution, engaged Buddhism yields significant impact on the formation of social trust. We carried out in-depth interviews in Vietnam with 33 organizational leaders who were Buddhist practitioners, using thematic analysis to elucidate our findings and arguments. The study reveals how the incorporation of Buddhist principles has fostered context-sensitive, non-extreme, and reflexive managerial approaches to enhance morality as a response to social trust issues.
\end{abstract}

\section{Introduction}

Trust, or social trust is often considered as "the expectation that arises within a community of regular, honest, and cooperative behaviour, based on commonly shared norms, on the part of other members of the community" (Fukuyama 1995, p. 26). Social trust is important as it not only promotes efficiency in market and economic growth, but also contributes to "the provision of public goods, social integration, co-operation and harmony, to personal satisfaction, to social integration, co-operation and harmony, to personal life satisfaction, to democratic stability and development, and even to good health and longevity" (For an overview, see Delhey and Newton 2003, p. 94). Theories on the determinants of social trust rest on two schools of thought (Delhey and Newton 2003). The first considers that trust is an individual

Mai Chi $\mathrm{Vu}$

mai.c.vu@northumbria.ac.uk

Trang Tran

trang.tran@auckland.ac.nz

1 Newcastle Business School, Northumbria University, City Campus East, Newcastle upon Tyne NE1 8ST, UK

2 University of Auckland Business School, Auckland, New Zealand property and that it is largely dependent on an individual's characteristics and demographic factors. The second asserts that it is social systems that determine social trust.

Individual theories of trust suggest that personality characteristics such as optimism and pessimism in particular determine individual willingness to trust others (Uslaner 1999). Optimistic individuals are more willing to cooperate and interact with others, whereas pessimistic individuals tend to doubt the positive outcomes brought by cooperation (Delhey and Newton 2003). Furthermore, individuals with high levels of job and life satisfaction, money, and status tend to trust others because they are treated with more respect and honesty. In contrast, individuals with lower status, income, and education tend to express dissatisfaction with life and lose trust in other people (Putnam 2001).

Social theories, the second broad approach toward trust, posit that individuals develop trust attitudes as they interact with other individuals in society, and social or political institutions support the development of trusting attitudes (Delhey and Newton 2003). Four theories fall under the umbrella of social theory. First, voluntary association theory suggests that involvement in voluntary organizations (e.g., religious) and associations can produce high levels of individual trust, collaboration, sympathy for others, and an understanding of the common good and interests. Social network theory, in 
contrast, asserts that social trust is developed through interactions with family, friends, and neighborhood, participation in social relations in the workplace, and participation in other informal networks (e.g., book clubs, support groups) (Delhey and Newton 2003). Third, community theory asserts that levels of trust correspond to characteristics of the communities where individuals reside, including community size and satisfaction. Putnam (2001) suggests that individuals who reside in small towns and rural areas are more trusting, honest, and altruistic than people in cities. Fourth is societal theory, which differs from community theory in that it focuses on the characteristics of whole nations. Countries with greater income equality, universal welfare, democratic government, and strong legal systems and enforcement are more trusting than others. According to Delhey and Newton (2003), these different theories are not mutually exclusive as their measurement indicators often overlap to some extent. Therefore, empirical studies can find support for several or all of these theories (Daniels and von der Ruhr 2010).

This paper uses institutional theory, a branch of societal theory according to Delhey and Newton's (2003) classification, to explore the role of engaged Buddhism in the formation of social trust. Our particular focus is on how religious forces (i.e., beliefs, values, and practices) contribute to the development of individual trust, and whether individuals are willing to extend such trust beyond their familiar networks. Societal theory is a good fit in this research context because the institutional environment of Vietnam, encompassing distinctive characteristics of volatility, uncertainty, complexity, and ambiguity (Bennett and Lemoine 2014), has fostered a movement toward religious and spiritual practices as guides for behavior. This paper aims to investigate the role of Buddhist principles in influencing the morality of managers engaging in interpersonal networks and interactions. We start with the research question: "How does engaged Buddhism influence managerial approaches in the low trust context of Vietnam?"

The aims of the paper are sixfold: (i) to briefly review the literature of institutions and social trust; (ii) to introduce a Buddhist interpretation of trust; (iii) to introduce the research setting; (iv) to introduce a pragmatic perspective based on skillful means as a response to social trust issues; (v) to present the methodological approaches and main findings of the study; and (vi) to provide further discussion, conclusions, and avenues for future research.

\section{Institutions and Social Trust}

Institutions are "the rules of game in society" that constrain or enable human behavior (North 1990, p. 3). Formal institutions comprising rules guide social actors to make acceptable decisions, which in turn minimize risk for them
(Peng 2002). However, institutional rules need enforcement mechanisms to drive individuals and organizations to follow established institutions (Scott 2014). Formal institutions have a significant influence on trust in many areas of social life and are particularly crucial in economic relations (Farrell and Knight 2003).

Trust can be defined as "a set of socially learned and socially confirmed expectations that people have of each other, of the organizations and institutions in which they live, and of the natural and moral social orders that set the fundamental understandings of their lives" (Barber 1983, pp. 164-165). It is also "a psychological state comprising the intention to accept vulnerability based upon positive expectations of the intentions of behaviour of another" (Rousseau et al. 1998, p. 395). When social actors make economic transactions they need to trust one another (Raiser 2003). This is especially the case for incomplete contracts, where one party cannot fully monitor the fulfillment of the other party's obligations under the contract. The risk of opportunistic behavior can prevent the exchange from happening altogether (Raiser 2003; Williamson and Kerekes 2011). Therefore, a lack of trust may generate high transaction costs and limit mutually beneficial transactions (Raiser 2003). Raiser (2003) suggests there are three types of relationship in economic transactions, and these produce three different kinds of trust. First is trading among kinship groups and family members. Such transactions are based on ascribed trust (Raiser 2003). Second is trading between members of a specific network who have known each other for a long time. In this case, transactions are repeated and trust is "process based" (Raiser 2003). Third is trading between strangers who enter transactions with limited information about their counterpart's attributes. Trading between these individuals requires "generalised or extended trust" (Raiser 2003). Effective legal systems prevent opportunism-the major source of insecurity in relationships and enable social actors to trust and cooperate with each other beyond their familiar networks (North 1987; Williamson and Kerekes 2011). In the context where formal institutions fail in their function, where laws exist on paper but are not enforced by the state, researchers have found that social actors are not willing to engage in capital investment and other productive behavior, and trade with strangers. They prefer to work in their kin groups in order to minimize the risk of their interests being expropriated by strangers (Claessens et al. 2002; La Porta et al. 1999).

However, it is not sufficient to consider only formal institutions as determinants of trust. Informal institutions, which are defined as "socially shared rules, usually unwritten, that are created, communicated, and enforced outside of officially sanctioned channels" (Helmke and Levitsky 2004, p. 727), play a significant role in establishing the necessary conditions for trust, trustworthiness, and cooperation (Farrell and 
Knight 2003). In the context where formal institutions fail to support social trust, informal institutions can become substitutes (Helmke and Levitsky 2004). According to Helmke and Levitsky (2004), substitutive informal institutions obtain what formal institutions were designed but fail to achieve. Table 1 presents empirical findings of substitutive informal institutions reported in literature.

Religion, one type of informal institution, can be an important source of social cohesion according to social scientists. Spiro (1966) defined religion as "an institution consisting of culturally patterned interaction with culturally postulated human beings" (p. 98). As an informal institution, religion encompasses socially shared patterns of behavior and belief (McGuire 2002). Most religions are comprehensive meaning systems or worldviews that provide individuals or groups with reasons, logics, or explanations for spheres of life to orient their actions. Individuals and social groups can rely on religion to give meaning to their existence (McGuire 2002). Attaching meaning to events is a human process (Berger and Luckmann 1967). An applied system of meaning enables individuals to recognize their identity, including their characteristics, the importance of the roles they perform, and the meaning of being who they are. For instance, a person may interpret an event by applying a variety of possible meanings. For example, losing one's job can be seen variously as "bad luck," "ethnic discrimination," or "God's will” (McGuire 2002, p. 26).

As a religion, Buddhism facilitates systems thinking that can significantly influence individual behavior and social phenomena (Midgley and Shen 2007; Shen and Midgley 2007). Religious participation is viewed as an important source of interpersonal networks and interactions. Welch et al. (2004) suggest that members of mainline Protestant denominations tend to display higher levels of social trust than individuals affiliated with specific dominations (e.g.,
Pentecostal and other Christians). Similarly, Fukuyama (2000) found that Protestant norms and values enable social trust to extend from close relationships to people in general. Religion can encourage democratic participation and cooperative behavior when individuals are willing to cooperate and trust others outside their network. It does so by promoting personal ethical codes such as honesty, truthfulness, temperance, compassion, and kindness, which are crucial for interpersonal interaction and cooperation (Hosmer 2008). According to Cohen and Dienhart's (2013) moral conceptions of trust, individuals or organizations are trustworthy if it is believed they are unlikely to exploit the trustor's vulnerabilities due to their moral character. Further, Soule (1998) asserts that trust can only be established through individuals executing negative and positive duties toward each other. Jones and Bowie (1998) also suggest that only individuals subscribing to ethical principles such as commitment and loyalty, and with a willingness to be vulnerable, can establish trust. Wicks et al. (1999) argue that "agents need to have stable and ongoing commitments to trust so that they share affect-based belief in moral character sufficient to make a leap of faith" (p. 103). By exploring how religion has an influence on individual morality in reciprocity and civic engagement, our paper responds to the call by Nielsen and Massa (2013) to discuss how institutions affect the morality of individuals, which in turn affects their behaviors.

Religion has major implications for social trust based on how it cultivates meaning-making that affects behavior. In the scope of our study, religion as an informal institution is interpreted as a source of sense-making, not a source of superstitious beliefs or dogmas. This paper seeks to investigate the role of Buddhism as mechanisms shaping managers' views on trust at the organizational level by exploring whether religion can support or hinder social interactions and cooperative behavior in Vietnam-the context of this

Table 1 Ineffective formal institutions and substitutive informal institutions

\begin{tabular}{|c|c|c|}
\hline Studies & Ineffective formal institutions & Substitutive informal institution \\
\hline Helmke and Levitsky (2004) & Legal systems & $\begin{array}{l}\text { Helmke and Levitsky (2004) assert that substitutive institutions are likely to } \\
\text { appear where formal institutions are ineffective. In China, for instance, local } \\
\text { officials supply public goods by mobilizing resources through temple and line- } \\
\text { age associations }\end{array}$ \\
\hline Estrin and Prevezer (2011) & Economic rules & $\begin{array}{l}\text { Estrin and Prevezer (2011) suggest that political connection is a substitutive } \\
\text { informal institution which facilitates private entrepreneurs to access bank loans } \\
\text { and government support }\end{array}$ \\
\hline Sauerwald and Peng (2013) & Legal systems & $\begin{array}{l}\text { Sauerwald and Peng (2013) highlight the role of national culture, especially a } \\
\text { collectivist orientation, and trust in principal-principal conflicts }\end{array}$ \\
\hline Horak and Klein (2016) & Economic rules and contracts & $\begin{array}{l}\text { Horak and Klein (2016) evidence that yongo-informal social networks in Korea } \\
\text { facilitate general trust in Korean society. }\end{array}$ \\
\hline Boytsun et al. (2011) & Legal systems & $\begin{array}{l}\text { Boytsun et al. (2011) indicate that informal rules such as social norms and social } \\
\text { cohesion have significant influence on corporate governance. That is com- } \\
\text { munities with stronger social norms will have more open firm-level corporate } \\
\text { governance }\end{array}$ \\
\hline
\end{tabular}


study. The following section discusses how formal and informal institutions relate to social trust in Vietnam.

\section{The Roles of Formal and Informal Institutions in Social Trust in the Vietnamese Context}

In Vietnam, the term transition refers to the movement away from a socialist centralized economy to a more market-led decentralized economy under the renovation policy "Doi Moi" (Painter 2006). 30 years after these economic reforms, Vietnam has become one of the world's fastest growing economies (ADB 2017). Over the past decade, the average rate of economic growth has been approximately $6 \%$, with growth projected to reach $6.5 \%$ in 2018 (ADB 2017). To a large extent, this dramatic growth has resulted from market mechanisms including economic stabilization, trade liberalization, and encouragement of private initiatives (Hoskisson et al. 2000).

Legal reforms are implemented to support economic development following renovation policies such as in Vietnam. An effective legal framework enables property rights among economic actors to be enforced (Gray 1997). However, there are major gaps between the content of legal frameworks and the enforcement capacity of authorities in Vietnam due to high levels of corruption (Vu et al. 2018). Vietnam is one of Southeast Asia's most corrupt countries, scoring 33 out of 100 on the Corruption Perceptions Index in 2016 (Transparency International 2016). Strong legal enforcement can threaten the benefits state officials receive from bribery. Consequently, laws exist on paper but are not complied with by the public or enforced by state officials (Gray 1997). Corruption is prevalent in societies suffering from moral degradation (Zheng et al. 2014). In such societies, people are inclined to "tolerate, accept, and even normalise immoral behaviours and perceptions" (Zheng et al. 2014, p. 406). Martin et al. (2007) also described how social actors are subject to pressures in a morally corrupt environment and this generates illicit activities like bribery.

Corruption can lead to low levels of generalized trust, as people are not willing to trust strangers ( $\mathrm{Li} 2009)$. According to Rothstein and Stolle (2001), the behaviors of state officials give important signals to citizens about the moral standards of the society. Therefore, social actors find that strangers are dishonest in much the same way as state officials in a society with a high degree of corruption (Rothstein and Stolle 2001). Moreover, social actors establish expectations of strangers' behavior based on the quality of the institutional system (Rothstein and Stolle 2001). Ineffective formal institutions cannot generalize trust among citizens because they fail to represent fairness, justice, and truth, and sanction dishonest behavior (Offe 1999).
The absence of generalized trust results in more reliance on particularized trust - trust between people from the same groups or networks in order to make social exchanges ( $\mathrm{Li}$ 2009; Rothstein and Stolle 2001). In a study on trust and interfirm relationships in Vietnam, Nguyen et al. (2005) found that mutual acquaintances facilitate the establishing of trust and relationships between two strangers. Particularized trust, however, raises ethical and moral issues as researchers have shown that people from inside networks distrust and ill-treat those from outside networks (Huff and Kelley 2005; Lee and Dawes 2005).

The transitional context in Vietnam has brought trust deficits at institutional, organizational, and individual levels. When formal institutions fail to ensure a degree of generalized social trust, religious traditions or spirituality can be an alternative positive influence on social trust. Religion has significant influence on moral beliefs and social norms in Vietnam because the Vietnamese are deeply rooted in their national identity (bản sắc dân tộc) through traditional spiritual folk practices and rituals known as the 'spirit side' (bên thánh). The spirit side includes ancestor worship (thò cúng tổ tiên), worship of the deified hero Trần Hưng Đạo, and appreciation of mother goddesses (thánh mẫu), the Jade Emperor (Ngoc Hoàng), holy sages of saints (thánh), or figures of the Chinese Daoist pantheon-including the Kitchen God (Ông Táo) (Soucy 2012). However, such practices reflect psychic phenomena (Nelson 2009) and are neither practical as a response to contemporary issues, nor applicable as solutions to the complex and dynamic relationships in the business environment. On the other hand, Buddhism has increasingly been engaged and diversified within social, economic, and religious activities (Nguyen 2009), as Buddhism is not about rituals or dogmas, but consists of practical and analytical practices that can be usefully applied in response to contemporary constraints and contexts. Engaged Buddhism in Vietnam refers to the application of the dharmaBuddha's teachings - to all sorts of contemporary suffering due to social, political, economic, or environmental issues caused by the transitional context (Thich 1998). Vietnam therefore provides a favorable context for exploring the impacts of engaged Buddhism on managers' views on trust issues in a contemporary transitional context.

\section{Interpretations of Trust and Social Trust from a Buddhist Perspective}

The current literature emphasizes that the concept of trust is mostly based on expectations regarding others' behaviors (Kramer and Lewicki 2010), which include socially confirmed expectations (Barber 1983), the "confident expectation that all persons involved in the action will act competently and dutifully" (Lewis and Weigert 1985, p. 971), the 
"expectation that the other will perform a particular action important to the trustor" (Mayer et al. 1995, p. 712), and "expectations that another's future actions will be beneficial, favorable, or at least not detrimental to one's interests" (Robinson 1996, p. 567). However, what happens if expectations about institutional and social conditions or even others' behavior are not met because external conditions are beyond individuals' control, such as in transitional economies with a one-party policy like China or Vietnam? Does this mean that trust is passively cultivated through expectations about external conditions?

Buddhism teaches that clinging onto expectations can lead to suffering and offers paths and means to eliminate suffering. In Fig. 1, we summarize and demonstrate the main principles of the Buddhist path toward attaining enlightenment (wisdom) for the cessation of suffering.

The Buddhist Four Noble Truths (Sanskrit: catvāri āryasatyāni; Pali: cattāri ariyasaccāni) illustrate the causes and forms of suffering within the dependent arising (Sanskrit: Pratītyasamutpāda; Pali: Paticcasamuppāda) nature of the universe-according to which all phenomena exist in interdependent relationships. Ignorance of the truths or reality of the universe can cultivate cravings and the need to cling onto certain forms of emotion and materialistic expectations that do not exist in static states. Ignorance of the Four Noble Truths results from a failure to acknowledge the three characteristics/markers (laksana) of existence, and thus all phenomena. These characteristics are impermanence (anitya) - the transient nature of phenomena; pain or suffering (duhkha) — dissatisfaction or stress in life; and the non-substantial or non-self (anātman) - or illusory existence of self/ego (Schroeder 2004). While trying to pursue illusionary static needs, individuals can set up consequences associated with their actions known as karmic consequences. As long as there are excessive desires and attachment to expectations, there will be suffering. The Four Noble Truths highlight the role of the Noble Eightfold Path (Pali: ariyo atthañgiko maggo; Sanskrit: āryāștāingamārga) for guiding Buddhist practitioners to overcome ignorance leading to suffering through the practice of eight principles: right speech, right action, right livelihood, right concentration, right mindfulness, right view, and right intention. This process involves the realization of non-self, and the state of emptiness (emptiness of inherent existence of phenomena) necessary for wisdom accumulation toward enlightenment. Buddhist practice "empties out the self" (Purser 2012, p. 24) through the concept of non-self, explaining that clinging desperately to self or a certain phenomenon can be a source of suffering and form of obsession (Ho 1995). Accepting the non-existence of self in turn facilitates realization of the emptiness of the universe in its dependent arising nature, which, combined with compassion, fosters the state of wisdom articulation toward enlightenment. This path toward enlightenment fosters the application and practice of a

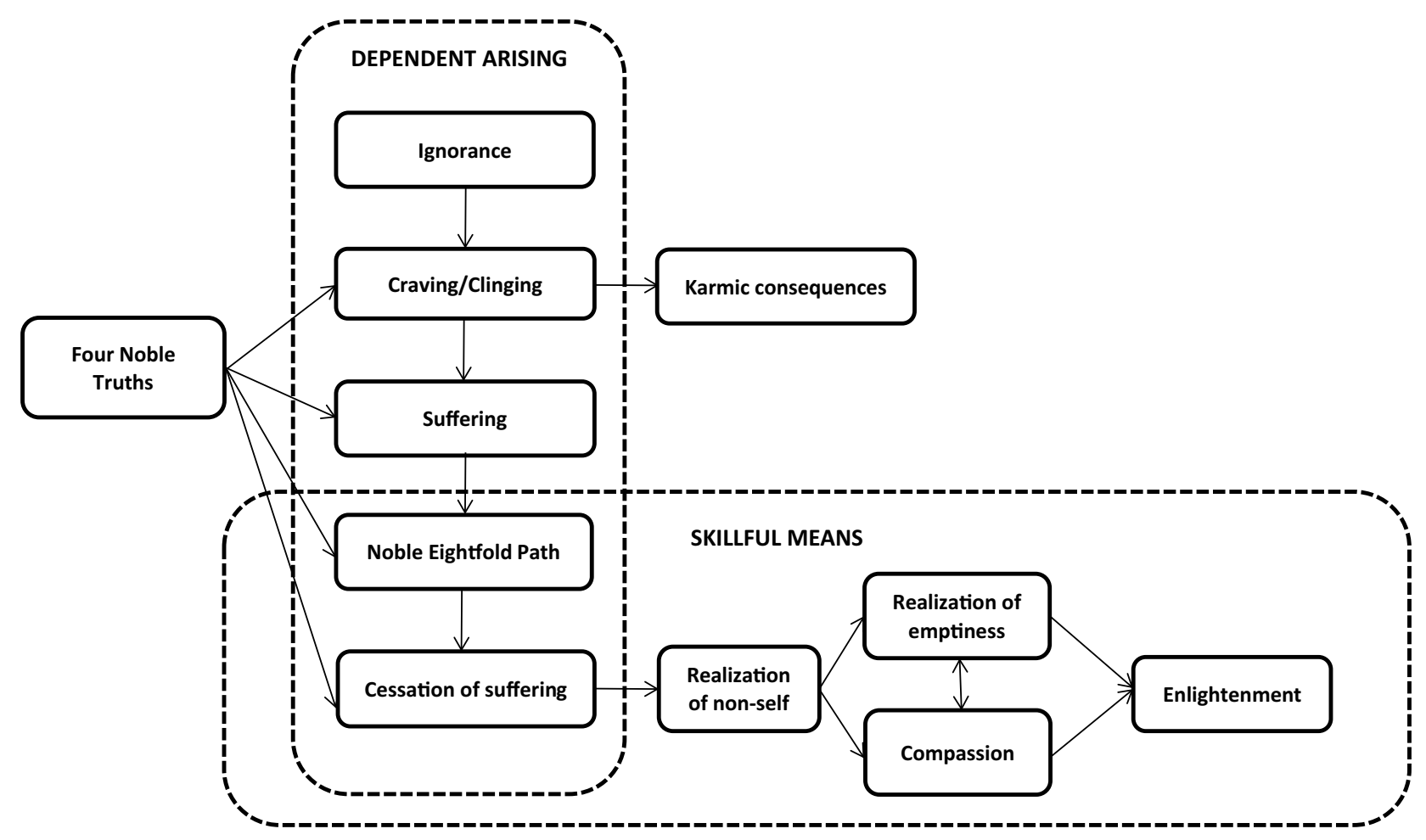

Fig. 1 An interpretation and summary of the Buddhist path toward enlightenment 
variety of skillful means to respond to impermanent contextual challenges. The concept of skillful means will be further demonstrated in the following sections of the paper (please also see Table 3 for further illustration of the main Buddhist concepts used in this paper) (Fig. 2).

Based on a Buddhist interpretation of the world, trust, as described in the Kālāmā Sutta (Anguttara Nikaya Vol. 1, pp. 188-193), emphasizes wisdom articulated trust, which refers to trust based on direct experiences of reality, and understanding the truth and dependent arising nature of the universe and how this influences the relationships and impermanent states of expectation that, in turn, shape trust. In other words, excessive attachment to expectations of others' behaviors or future actions can be the direct cause of suffering through lack of trust, rather than merely being due to external factors. However, there is a limited literature conceptualizing and examining trust from a Buddhist perspective. We will introduce a Buddhist view of trust to examine the underlying assumptions conceptualizing social trust and what leads to lack of trust.

By introducing a Buddhist view on trust, it is not our intention to reject the established literature on trust based on attachment and expectations. We acknowledge that there are healthy forms of attachment in organizations that can foster personal development in general, including by cultivating trust through secure attachment (Game 2011). Western interpretations of attachment originate from Bowlby's (1969) attachment theory, and mostly refer to attachment as having
Fig. 2 Data structure for interview respondents

\section{First Order Concepts}

\section{Second Order \\ Themes}

\section{Aggregate \\ Dimensions}

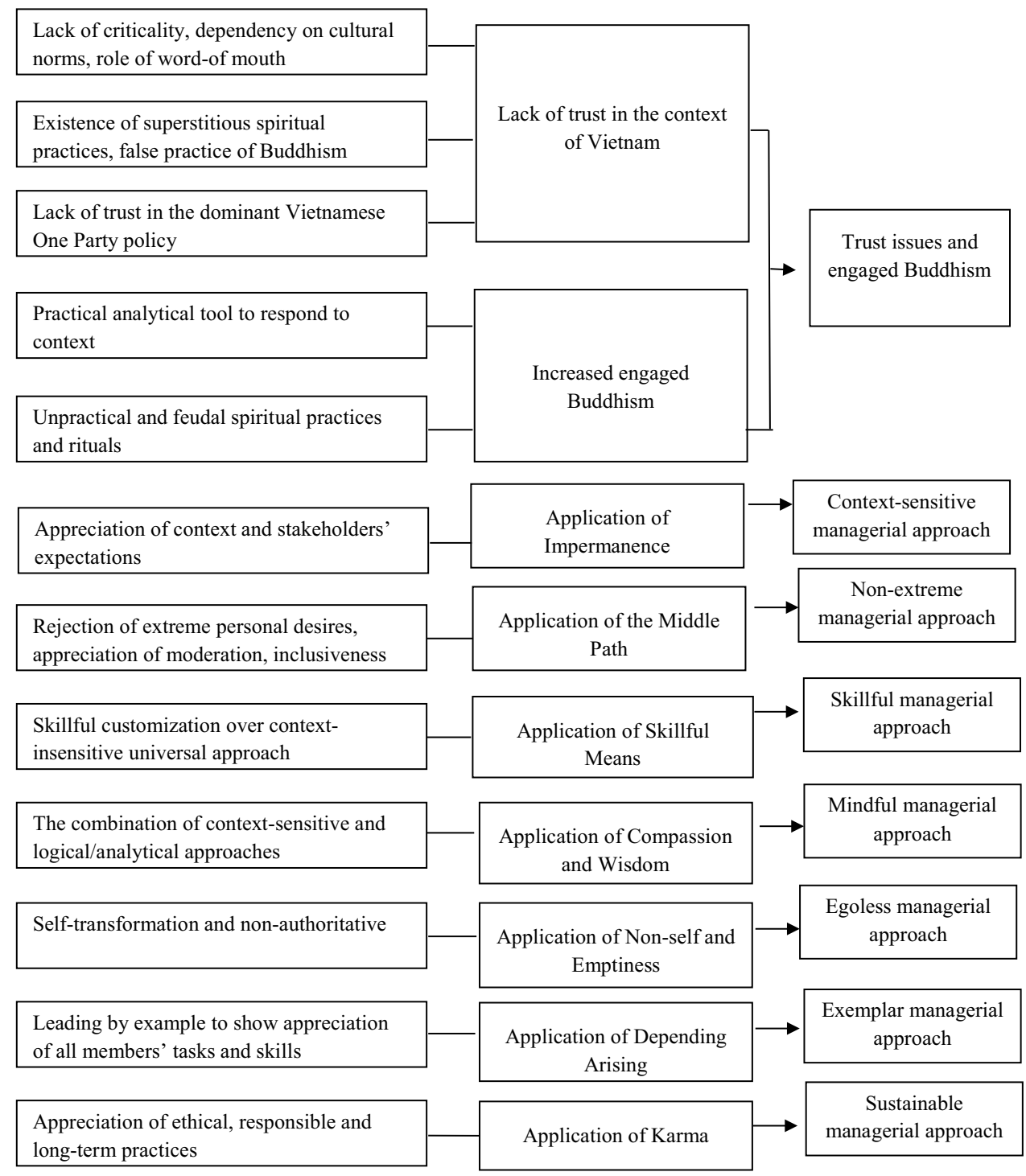


positive connotations of security and feelings of being loved (Mikulincer and Shaver 2007). On the other hand, the same term in Buddhism reflects grasping and clinging behavior (Wallace 2005) as any form of immoderate desire and ignorance can lead to suffering and karmic consequences. What we are emphasizing here is that excessive forms of attachment to what the 'self' perceives, believes, and expects to be righteous may eventually turn into suffering despite the impermanent nature of all phenomena. For instance, in relation to leadership, fantasizing about the existence of a self or ego can trigger egocentric or ideal portrayals of leaders, which can then lead to the self- aggrandizement and grandiosity associated with narcissism (Steyrer 2002), also known as phantasmic attachment (Jones and Spicer 2005). Likewise, the pursuit of trust at any cost can lead to suffering because trust is inevitably attached to expectations, and according to the notion of dependency arising, the conditions associated with the fulfillment of such expectations are dependent on a variety of factors that are beyond individual control.

As a response to immoderate or extreme desires, the Middle Way (Path) (Pāli: Majjhimāpațipadā; Sanskrit: Madhyamāpratipad) in Buddhism represents a moderate approach that avoids the extremes of self-mortification and indulgence, and gives full moral weight to conflicting values (Schroeder 2004). The Buddha himself learned through experience that attaining enlightenment through extreme measures such as self-mortification and indulgence is not sufficient. Therefore in Buddhism, the achievement of wellbeing in human life lies along the path between the two extremes of self-indulgence and self-asceticism and their associated obsessions (Gunasekara 1982; Niwano 1980). The Middle Path in Buddhism entails avoiding anything which is too extreme, and considering the righteousness of ethical principles and practical decisions and outcomes that may appear extreme or unethical at first, but are necessary for the longer term, and to avoid other decisions that may be even be more extreme (Midgley and Shen 2007). It is a dynamic middle position (Combs et al. 2002).

What does this mean for understanding and interpreting trust? If trust is based on expectations of a static-desired phenomenon, then interpreting trust from the basis of excessive attachment to expectations about external conditions (i.e., strong legal system) to fulfill one's hopes can create suffering and disappointment, leading to lack of trust because external conditions (both formal and informal institutional forces) are impermanent and beyond individuals' control. The Middle Way suggests a dynamic middle position in interpreting trust; a context-sensitive view of trust based on the understanding that trust is dependent on both external and internal factors. Rather than an impractical reliance on impermanent external conditions to cultivate trust, there are proactive means that individuals can apply to enhance trust.
It is important to understand that any form of social trust is not a static norm, but needs to be articulated based on an understanding of the impermanent nature of the universe, and so personal reflexivity is required to cultivate contextsensitive approaches to enhance trust. In other words, neither having definite expectations of what others should do to build up trust regardless of changes in external conditions, nor having a static view of what constitutes trust is realistic, especially in complex contemporary organizational contexts.

\section{A Pragmatic Perspective and Skillful Means Approach to Respond to Social Trust Issues}

As highlighted above, rather than relying on excessive expectations of external conditions (i.e., formal institutions such as legal enforcement) that are beyond individuals' control, Buddhism provides principles that can be applied proactively to respond to external challenges associated with trust issues. Bachmann et al. (2015) suggest that organizational and institutional approaches to respond to trust issues are context-bound, thus context-sensitivity plays an important role. According to pragmatists, "problems do not come neatly defined" (Ferraro et al. 2015, p. 369); defining a problem is a process, and an essential guide to possible resolutions. Therefore, means and ends are subject to change depending on the context, and "humans are problem solvers and the function of thought is to guide action in the service of solving practical problems" (Gross 2009, p. 366). Likewise, attending to social trust issues in contemporary complex institutional and organizational contexts requires pragmatism, in that it fosters the "philosophy of evolutionary learning, the ability of both individuals and communities to improve their knowledge and problem-solving capacity over time through continuous inquiry, reflection, deliberation and experimentation" (Ansell 2011, p. 5) to generate context-sensitive ways of responding to trust issues based on reflexive experiences.

Buddhism further demonstrates this pragmatic approach through the concept of skillful means. Skillful means (Sanskrit: upāya), based on the notion of non-attachment in Buddhism, refers to the technique that the Buddha used to deliver his teachings in various ways in response to the different contexts of his audiences (Federman 2009a, b; Schroeder 2004, 2011). Skillful means indicates no single way of teaching or leading is sufficient because due to the impermanent nature of the context, a preference for or excessive attachment to a specific approach is a form of suffering in Buddhism. For instance, when asked about his teachings, the Buddha offered answers and explanations or reprimands for some; however, for others he just kept silent, matching the significance and appropriateness of his answers to the context of his audience (Murti 1955; Organ 1954) to avoid 
confusion or misinterpretations (Schroeder 2004). The Buddha's intention was therefore to teach non-attachment through skillful means. He showed that wisdom is embodied in how one responds to others and applies Buddhist teachings rather than being about a conception of the universe, thus revealing context-sensitive approaches that can respond to concerns about contemporary issues. In contemporary contexts, Buddhist practitioners apply Buddhist teachings known as the dharma to respond to various facets of challenges in all aspects of life to alleviate suffering. Thich (1998) referred to these interpretations of Buddhist doctrines and practices as rafts-or skillful means. The intent here is to articulate mindful wisdom-based reactions to handle desires that can lead to suffering in contemporary contexts.

The concept of skillful means is somewhat similar to Aristotle's typology of phronesis (prudence); that is, applying practical wisdom to direct individual activities toward the common good of the community (Porter 1994) by aiming at good ends "making use of clever instrumental reasoning" (Kraut 2006, p. 7). Practical wisdom is "a disposition toward cleverness in crafting morally excellent responses to, or in anticipation of, challenging particularities" (Moberg 2007, p. 536). In other words, there is more than one response to a set of particularities, which sometime present moral dilemmas between valued alternatives (Badaracco 1997), resulting in tradeoffs between justice and mercy, short- and long-term consequences, self and community, and truth and loyalty (Kidder 1995). Similarly to practical wisdom, skillful means guides practitioners to selectively, mindfully, and skillfully apply Buddhist principles in a context-sensitive manner. For instance, practical wisdom may be reflected through inaction, since sometimes no action is the wisest action (Tykocinski and Pittman 1998) as shown by the Buddha using his 'noble silence' to respond to variations in the context of his audience (Schroeder 2004). This approach can be usefully applied to context-bound approaches to social trust issues and moral dilemmas, and especially in leadership and managerial responses as it facilitates the factual knowledge needed to understand and deal with the pragmatics of life that are a feature of the epistemic uncertainty of the contemporary business environment, where consideration of long-term benefits and the infusion of virtue are crucial (McKenna et al. 2009). A study by Sosik et al. (2012) shows that wisdom and virtues such as integrity contribute significantly to the performance of executive because wisdom and knowledge shape perspectives and social intelligence, which in turn can enhance leadership effectiveness through the ability to learn and change (Boal and Hooijiberg 2001; Hooijberg and Schneider 2001). Therefore, exploring how the application of Buddhist practice and wisdom might influence managers' approaches in response to social trust issues in the complex transitional context of Vietnam contributes to wisdom-related research that acknowledges the significance of knowledge, perception, and truth for the management of contemporary organizations (McKenna et al. 2009; Luthans and Youssef 2007).

Buddhism has various principles and practices to guide practitioners in understanding both the self and external phenomena to cultivate wisdom. However, individuals require a skillful means approach and skillful interpretation to evaluate the relevance of such principles and practices and then adopt a context-appropriate approach. Accordingly, in transitional or complex contexts, responding to trust issues requires a skillful and pragmatic approach to grasp their underlying causes. Table 2 introduces selected Buddhist principles and demonstrates their roles and practicability in attending to social trust issues.

How these approaches are perceived and applied in practice is evidenced in our data analysis of perspectives gathered from managers.

\section{Methods and Sampling}

Due to the exploratory nature of the research into trust approaches in a transitional context from a Buddhist perspective, we conducted a qualitative research study based on an interpretive naturalistic approach to the subjects and phenomena (Denzin and Lincoln 1994). We interviewed 33 senior executives in various industries in Vietnam, following Lincoln and Guba's (1985) guidelines for purposeful sampling to recruit respondents who were Buddhist practitioners.

At first in our initial pilot study, we wanted to differentiate between Buddhist and other respondents. However, we faced three main obstacles that lead to our decision to restrict the sample to Buddhist respondents. First, it was not straightforward to differentiate between spiritual and Buddhist organizational leaders because the term 'spirituality' in Vietnamese (tâm linh) departs significantly from Western understandings. Some respondents referred to spirituality as superstitious practices rather than values, while others understood it as a common form of ritual-embedded sensemaking. Second, we found that respondents who identified themselves as spiritual showed superstitious beliefs in representing folk traditions and a separation between spiritual beliefs and managerial practices, which was not what we were seeking to explore. Third, some respondents identified themselves as spiritual, but later on in the conversation referred to Buddhist practices. Furthermore, in the pilot study, we also explored the views of six non-Buddhist managers to get a sense of what they thought about trust issues in the business environment in Vietnam. While expressing similar concerns to Buddhist managers in their interviews, the non-Buddhist respondents tended to restrict their activities to within relational ties and networks. In their view, trust 


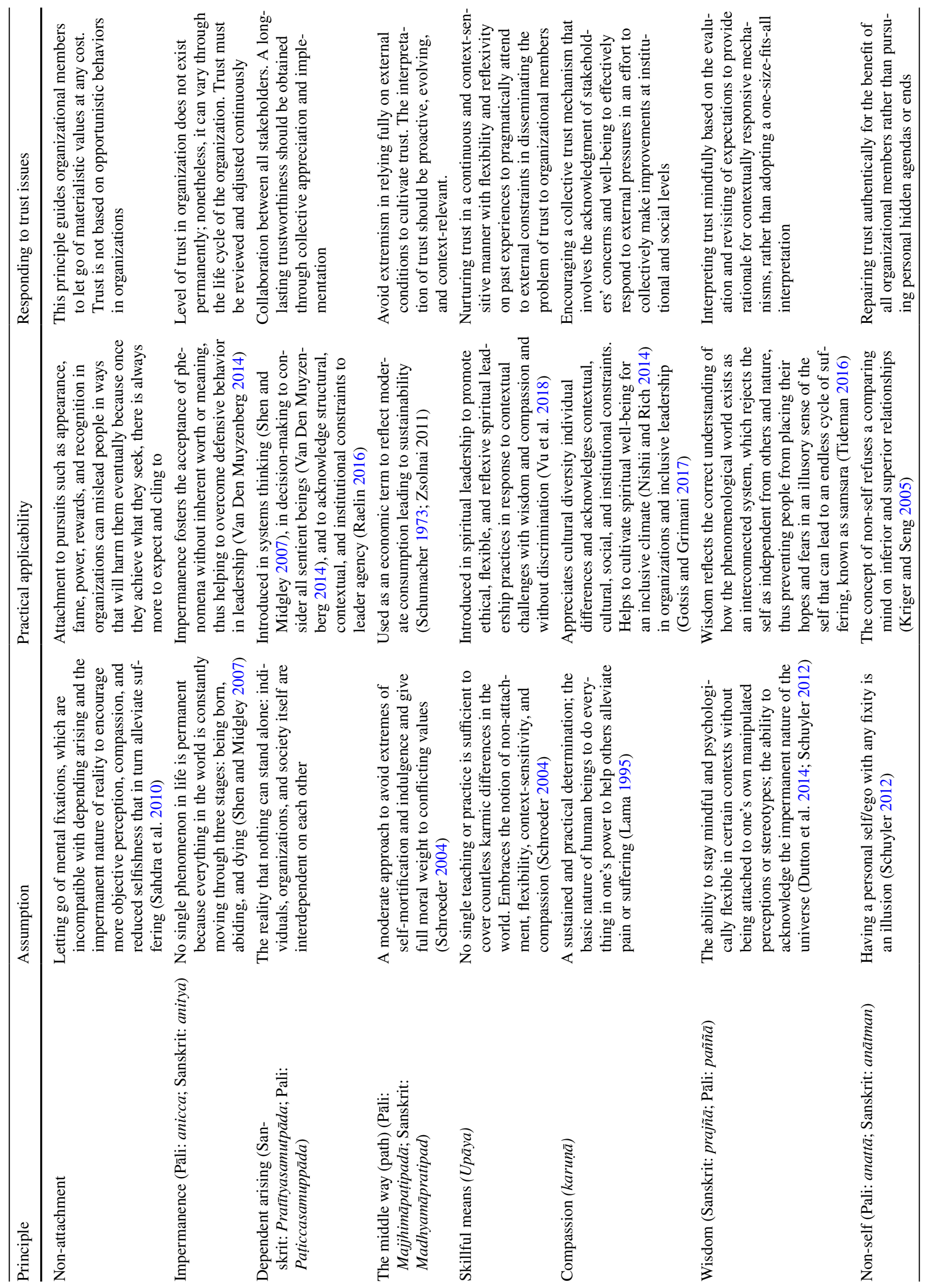


only exists among acquaintances such as friends and family. Buddhist respondents on the other hand focused on how they applied Buddhist principles to respond to trust issues in the wider environment and what tensions they faced along the way. Buddhist practices were thus highlighted as providing reasonable guidelines for behavior in an environment of trust deficit. The inclusion of a counterfactual group in the pilot study will make the findings on the relationship between Buddhism and trust in a developing context more robust. However, given the intent of our study was to further explore the influence of the rise of the engaged Buddhist phenomenon as a now almost 'fashionable' practice in the transitional context of Vietnam, we chose Buddhist practitioners as our main sample.

To identify our respondents, we found the snowball technique very useful. In our pilot interviews in July 2016, we identified a number of Buddhist leaders who were members of Buddhist business-oriented groups. Because Buddhist practitioners are often involved in Buddhist communities, we asked respondents to recommend other members from their communities. The respondents for our final official interviews in November came from various industries and sectors and had many years of experience in managerial and leadership roles, thus contributing to the dynamic outcomes of the study. Each interview lasted for between one and two hours. Table 3 shows details of the interview participants.

Semi-structured in-depth interviews were used to capture the complex nature of managerial behaviors and initiatives, and to enable in-depth exploration of senior executives' approaches and experiences in tackling the distinctive context of the contemporary Vietnamese business environment. This interviewing method enables researchers to have interactions with their participants (Silverman 2011). Through the interactive process, the participant provides the information, and the researcher interprets and understands the information. Moreover, researchers build a relationship with participants in order to obtain deeper insight into a phenomenon and add richness and depth to the data (Ulin et al. 2004).

The interviews were guided by a schedule that allowed a high degree of flexibility for both the interviewer and interviewee (Bryman and Bell 2003). To facilitate in-depth interviews, the interview process was highly interactive, involving collaboration between the interviewer and interviewees to construct meaning and narrative together, with the interviewer "activating, stimulating and cultivating the subjects' interpretative capabilities" (Holstein and Gubrium 1997, p. 122). The interviewer also gave the respondents opportunities to be active: "[a respondent] not only holds facts and details of experience, but in the very process of offering them up for response, constructively adds to, takes away from and transforms the facts and details," and it is the interviewer's job to 'harness respondents' constructive storytelling for the research 
Table 3 Summary of respondents

\begin{tabular}{|c|c|c|}
\hline \multicolumn{2}{|c|}{ Respondent } & \multirow{2}{*}{$\begin{array}{l}\text { Sector } \\
\text { Construction }\end{array}$} \\
\hline 1 & CEO and Managing Director & \\
\hline 2 & CEO and Managing Director & Information Technology Consultancy \\
\hline 3 & CEO & Printing and Publication \\
\hline 4 & Regional Manager & Education (BC) \\
\hline 5 & CEO and Managing Director & Pharmaceutical \\
\hline 6 & Doctor, CEO, and Managing Director & Medical Practice \\
\hline 7 & CEO and Managing Director & Health and Beauty \\
\hline 8 & CEO and Managing Director & Security Technology and Solutions \\
\hline 9 & CEO and Managing Director & Manufacturing \\
\hline 10 & CEO and Managing Director & Consultancy \\
\hline 11 & Regional Manager & Consultancy and Management \\
\hline 12 & CEO and Managing Director & Agriculture \\
\hline 13 & General Manager & Real Estate \\
\hline 14 & CEO and Managing Director & Retail \& Wholesale \\
\hline 15 & CEO and Managing Director & Media \\
\hline 16 & National Project Manager & Wastewater \\
\hline 17 & CEO and Managing Director & Agriculture \\
\hline 18 & National Manager & Pharmaceutical \\
\hline 19 & CEO and Managing Director & Publishing \\
\hline 20 & CEO and Managing Director & Food \& Drink \\
\hline 21 & CEO and Managing Director & Transportation \\
\hline 22 & Lawyer, CEO, and Managing Director & Corporate Law Consultancy \\
\hline 23 & CEO and Chief Accountant & Construction \\
\hline 24 & CEO and Managing Director & Communication \\
\hline 25 & National Manager & Energy \\
\hline 26 & National Manager & Hospitality \& Services \\
\hline 27 & Regional Manager & Distribution \\
\hline 28 & CEO and Managing Director & Talent Management Consultancy \\
\hline 29 & Health and Safety Manager & Oil \& Gas \\
\hline 30 & CEO and Managing Director & Telecommunications \\
\hline 31 & Economic Inspector & Economic Security Bureau \\
\hline 32 & CEO/Member of Board of Directors & Transportation \\
\hline 33 & CEO and Managing Director & Education \\
\hline \multicolumn{2}{|c|}{ Pilot Interviews (non-Buddhist practitioners) } & Sector \\
\hline 1 & Director & State Financial Investment \\
\hline 2 & CEO/Chairperson & Coffee Processing \\
\hline 3 & CEO/Member of Board of Directors & Sea Transportation \\
\hline 4 & CEO/Chairperson & Livestock \\
\hline 5 & State Official & Ministry of Finance \\
\hline 6 & State Official & $\begin{array}{l}\text { Business and Management Innova- } \\
\text { tion Department }\end{array}$ \\
\hline
\end{tabular}

task at hand" (Holstein and Gubrium 1997, pp. 117, 125). Throughout the interactive interview process for our study, interviewer and interviewees were conversational partners. For instance, we had interesting conversations with the interviewees regarding the effect of Buddhist practices on their behavior in ethically conflicting situations such as using bribery in order to sustain the business. As the respondents explained how they apply Buddhist practice in viewing bribery as a reasonable way to do business, we as researchers listened, captured their ideas, and extended the conversation by asking questions to seek clarification or in-depth meanings around their understanding of such practices and analyze their application of Buddhist practices in each particular situation. 
Probing questions to invite further detail or overcome any initial resistance and vagueness were asked to clarify respondents' answers. Depending on the participants' experiences and responses (Bryman 2013), there was space for follow-up questions to reveal underlying assumptions and gain information on unexpected interesting phenomena emerging during interviews. The interviews were conducted face-to-face in different parts of Vietnam in October and November 2016. All interviews were recorded, transcribed, and double translated for analysis.

To gain a holistic picture of the Vietnamese transitional context and issues of trust within society, we relied on openended and follow-up questions to enrich our understanding of the context and managerial approaches in response to trust issues. The interview questions were divided into two main parts. The first part asked general demographic information of respondents and verified whether they were Buddhist or had a spiritual background. The second part asked six main questions on the impact of the transitional context on managerial approaches and it was guided by various follow-up questions where needed. We first asked respondents: "How would you describe the Vietnamese contemporary transitional context today?" This question offered the opportunity for respondents to describe and explain institutional, social, and cultural aspect of the transitional context. We then asked: "To what extent does the transitional context affect your organization and managerial approaches," to explore impacts of context on organizations. Here, respondents shared dynamic experiences based on various industries and we further explored those answers with numerous follow-up questions. Lastly we asked a series of questions to examine managerial approaches to tackle challenges of the transitional context in Vietnam (e.g., "How do Buddhism and spirituality fit with your managerial approaches in the transitional context?" "How do you as a leader or manager handle challenges of the transitional context?" "To what extent have these measures been effective?" "What is the most difficult challenge that you have faced and how did you overcome it?" "How would you describe the nature of your workforce in the transitional context of Vietnam?" "How have employees' expectations changed and how does that impact your role as a manager/leader?"). We had one main question in our final interview protocol that referred to Buddhism. We did not include specific questions asking about Buddhism because after our pilot interviews, we realized that different respondents followed very different Buddhist practices depending on their chosen Buddhist path (Theravada, Mahayana, or Vajrayana) and the nature of their work. Therefore, it was not appropriate to ask specific Buddhist questions. Instead we asked the general question and then invited respondents to further elaborate on their specific Buddhist practices. In the follow-up questions on Buddhism, we asked questions based on what respondents had specified as their practices. Some respondents listed various principles so we asked them to explicitly demonstrate their application of each principle (e.g., "Can you explain how you applied the concept of non-self in your management to foster positive interpersonal relationships?" "To what extent has the Middle Way influenced your management practices and can you elaborate?", "Why is impermanence a significant factor in your management?"). At the end of the interview, we encouraged respondents to raise and share any other information they felt was important that had not been covered during the interview.

Thematic analysis was used (Daly et al. 1997) to analyze the data, combining a data-driven inductive approach to explore themes in the interviews and a deductive approach to organize data into systematic and relevant code types. Systematic coding and categorizing of the large amounts of textual information according to frequency, trends, and patterns in the words and phrases used identified their relationships in the discourse (Pope et al. 2006). Comparison techniques were also used (Glaser and Strauss 1967) to identify delineating themes and aggregate dimensions (Gioia et al. 1994). First, we read through the data several times to achieve immersion and obtain a sense of the whole (Tesch 1990). Second, we took $10 \%$ of the sample (three transcripts) to develop initial coding (Schreier 2012) through open coding. Third, we grouped initial codes into subcategories and categories to develop the initial coding frame and agree on the rules for determining which pieces of data could be included in which category.

The final data analysis for this study occurred in three stages. In the first stage, open coding was used to explore all possible alternative meanings of the data. The preliminary categories included common institutional and social concerns, spiritual movement, moral degradation, and trust issues, to name a few. These categories were revised continually to make sure that all data were represented. In the second stage, axial coding was used to connect concepts in the first stage and explore relationships between categories to suggest abstract and theoretical categories. For instance, institutional, social, and commodification challenges led to spiritual and trust issues within the context. In the last stage of data analysis, we examined how theoretical categories fit with literature to identify aggregate theoretical dimensions, particularly the nuances of managerial approaches in responding to social trust issues. The following figure (Fig. 1) details the data structure of the study.

Our findings revealed that a lack of trust in Vietnam is affecting managerial behaviors. Managers tend to either play it safe, or become more proactive by introducing skillful managerial initiatives that involve a role for spirituality and the application of Buddhist practices in management and leadership to respond to social trust issues. Below, we unpack the assumptions underlying trust issues in the 
context of Vietnam for Buddhist practitioners and introduce managerial approaches in response to such concerns. To illustrate how Buddhist practitioners showed a more positive orientation to tackling trust issues, we have included a number of findings from the non-Buddhist practitioners in our pilot study for comparison.

\section{Lack of Trust and Engaged Buddhism in the Vietnamese Context}

Our respondents who were Buddhist practitioners believed that the lack of trust within the Vietnamese context is due variously to weak legal systems, poorly functioning bureaucratic systems, institutionalized corruption, and the heavily relationship-dependent culture (quan hệ). Businesses partly depend on political connections, specifically how expertly their organizations 'take care' of relevant state officials in various ways. In our pilot study with non-Buddhist practitioners, we found similar strong concerns, especially issues with internal trust which have affected relationships; relationships and trust are the two core factors of the Vietnamese business environment. For example, a director of SAC emphasized the importance of trust in the business environment:

I was assigned to represent the state capital in one privatised company. When I was sitting on the board of directors, the other directors who were managers of the company considered me an outsider. They were reluctant or hesitant to share company information with me. Indeed, it took a lot of time to earn their cooperation. I had to show them that I was there to help them make the company better...I provided training on ways of developing the marketing department, and showed them how to procure materials by engaging in bidding. Eventually, when they did not see any selfinterest from me, they gradually began to cooperate.

The issue of internal trust manifested in the structure of the companies of non-Buddhist practitioners. Large shareholdings in IMEX and TUS were made up of family members and acquaintances. IMEX chose one investor, who had previously been a supplier, to become the company's strategic investor. Because they had an established long-term relationship, they trusted each other:

The strategic investor has been working with the company for a long time - they used to be the company supplier in the auto mobile industry. We trust each other. We have the same objectives and interests for the company. This is the reason we decided to choose a former business partner as our strategic shareholder. (CEO, IMEX)
Similarly, another company in our pilot study, TUS, had multiple large shareholders with long histories of dealing with each other (more than 10 years). These multiple large shareholders had built trust among themselves according to the $\mathrm{CEO} /$ director. There were under 100 shareholders in TUS. When capital was needed, TUS preferred to sell shares to current shareholders, or selectively chose other outside shareholders. Listing the company on the stock exchange was seen as a last resort:

We are not a public company. As a result, not all people can buy shares in our company. We only sell shares to current shareholders. If any large shareholder refuses to buy shares, the company will find other ways to sell shares. We selectively choose outside shareholders who have the same objectives and interests. If there is no trust, there are no successes. Listing the company in the stock market would be the last option. (CEO/ director, TUS)

Due to the value put on trust in the business environment, local investors preferred to buy a large number of shares to control companies as it is seen as unwise to have capital held by strangers. They followed the traditional wisdom that money is best managed and utilized by its owners; otherwise, they would rather put their money into saving accounts. This attitude is evidenced in the following remark by the deputy head of Ho Chi Minh City's business management and innovation department:

Most Vietnamese would say financial assets must always be kept and managed by their owners. Therefore, I want to become a controlling shareholder in the company to monitor my capital. I do not allow other individuals to spend my money. It seems risky if I cannot make decisions, or my ideas are not important to the company. If I can't be a controlling shareholder, I would rather put my money into a savings account.

Due to lack of trust in the business environment, a nonBuddhist informant in our pilot study said they would not want to appoint an individual to the board of directors who did not have any connection with the company. They were unwilling to allow strangers to hold or monitor capital when trust was not established. Trust and relationships are both significant to doing business in Vietnam. Shareholders feel more comfortable working with their acquaintances. They therefore vote themselves and their acquaintances onto the boards of directors, as described below:

The Vietnamese often say that money must stick to its owner. Therefore, I am not willing to vote for a stranger to become an independent director. I do not trust an individual I have no previous connection with. I cannot predict their performance in my company (Director, 
SAC; Director, IMEX; Director, TUS; Chairperson/ CEO, LIVES; State Official).

While issues of trust were addressed by both the non-Buddhist managers in our pilot study and the Buddhist managers and practitioners making up our main sample, we found that non-Buddhist managers were reluctant in responding to and solving trust issues (see above examples). On the other hand, our Buddhist respondents expressed a strong orientation toward applying Buddhist practices to improve trust-related issues.

I know that to be able to trust others is serious concern nowadays. It is not something you can deal with in the short term, however since I started practicing Buddhism, I have started to look at things positively. It has helped me to trust as well as to gain trust from others. (CEO \& Managing Director of a manufacturing company)

Most of the leaders in our study found the Buddhist principles of non-attachment (không bám chấp), cause and effect (nhân quả), impermanence (Pāli: anicca; Sanskrit: anitya) (vô thu'ơng), mindfulness (Pāli: sati; Sanskrit: smrti) (chánh niệm), and so on to be effective and adaptable principles for handling the complexities of the Vietnamese context to address trust issues. For instance, the CEO of a law firm described her effective application of the Buddhist principle of karma, as below:

Understanding causal effect helps me to achieve objective observation of my cases, and see the contexts and the relationships within the contexts. It is very important for me as a CEO and corporate lawyer to see the tricky layers of my business cases and be able to consult with my clients $[\ldots]$ and use the resulting strong analytical capabilities to build up a trusting relationship with my clients, which is very important for our collaboration in law.

Respondents also highlighted two main problems associated with this Buddhist phenomenon: (1) the lack of critical thought in the Vietnamese culture-leading to superstitious beliefs and commercialization of Buddhist practices as acknowledgement of the reciprocal relationships between the supernatural and people; compounded by (2) the collectivist 'word-of-mouth' culture which has negatively popularized superstitious beliefs. A manager of a transportation company explained why most Vietnamese people find it hard to differentiate between traditional spiritual practices as forms of spiritualism and Buddhist practices, highlighting the main reasons for the misguided understanding, commercialization, and practice of Buddhism in Vietnam:

Vietnamese people have a culture of respecting and accepting elderly people's advice, sometimes without hesitation or further investigation. However, elderly people tend to embrace traditional spiritual practices and often consider logical Buddhist principles as part of those practices. [...] many people falsely practice Buddhism as rituals dependent on reciprocal relationships and offerings (cúng dường). It has become even more problematic when Buddhism today is uncritically disseminated within a mass audience. It has become a trend, a movement focusing on quantity rather than quality. [...] There are levels of practicing Buddhism. Buddhist practice is based on life experience, thus students cannot be taught in the same way as managers or CEOs. Popularizing Buddhism for a mass audience is therefore ineffective and occasionally can be counterproductive, leading to ill-judged and fallacious practices.

Skepticism toward the system has ironically rendered uncritical dependency on cultural norms, such as following elderly people's advice unquestioningly despite the context, reflecting a feudal (phong kiến) system that is no longer practical in contemporary contexts. In the Vietnamese context, spirituality has its own national identity and some spiritual practices, such as 'going into trance rituals' (lên đồng) and using mediums (hầu đồng), are forms of spiritualism rather than spirituality, as they seek contact with spirits and psychic phenomena (Nelson 2009). Some traditional spiritual practices in Vietnam reflect "superstition, nostalgia or exoticism rather than a rational means to cope with the impositions of modern life" (Dickhardt and Lauser 2016, p. 3).

Our respondents stressed that their practices are more about philosophical viewpoints and have nothing to do with rituals or religions, as generally understood by the Vietnamese through the controversial term 'spirituality.' This reflection is similar to how scholars see Buddhism: Buddhism has no dogmas, no rituals, no worship, no savior, no personal deity, no god, but instead consists of set of practices and guidelines for living life that one might find useful to apply (Khantipalo 1992; Nyanaponika 1986; Rahula 1974). In addition, spirituality does not necessarily have roots in religion because it is "concerned with qualities of human spirit-such as love and compassion, patience, tolerance, forgiveness, contentment, a sense of responsibility, a sense of harmony - which bring happiness to both self and others" (Dalai Lama XIV 1999, p. 22). However, as a nation with a strong folk culture and belief in spiritualism extending over generations, false Buddhist practices and misinterpretations of spirituality are evident in Vietnam. This was one of the main reasons we found it challenging to explain the term 'spirituality' when trying to recruit spiritual respondents in our pilot study. In other words, being mindful of engaged Buddhist practices helps one to differentiate between Buddhist philosophical practices and superstitious practices. 
It is evident that people's lack of trust in the Vietnamese system has stimulated spiritual yearnings and engagement with Buddhism in particular. The fundamental causes of lack of trust in our findings are the weak role of formal institutions in the context of Vietnam and the growing individualistic and materialistic orientations within society. Paradoxically, while Vietnam has long embraced Confucian collectivism in its culture, the modernization and transitional processes occurring in Vietnam reflect a combination of both collectivism and individualism (Bond and King 1985; Ralston et al. 1999). As such, the informal institutions of practicing spirituality and spiritualism have deeply influenced the Vietnamese people. Engaged Buddhism has emerged from an awareness of the feudal and superstitious aspects of spiritual folk practices and spiritualism in the contemporary transitional context of Vietnam, and the need to respond to the increasing emphasis on individual achievement in the post-war period, despite the long-held collectivist culture (Quang 1997). A respondent with more than 15 years of Buddhist practice shared that Buddhism is greatly needed in the contemporary context of Vietnam because "it is just the right practice for selfcorrection (tu sủa bản thân) for individual materialistic desires." What we see here is that individualistic pursuits have gradually emerged from a collectivist culture due to the lack of security caused by the way the genuine intent of Confucian collectivism has been falsely applied to nurture unethical institutional corruption.

However, any emerging movement has two sides and the engaged Buddhist phenomenon in Vietnam is not without limitations due to some existing cultural norms and traditions. As the respondent above mentioned, there are two interpretations of Buddhism in the context of Vietnam: (1) the philosophical perspective of the practical application of Buddhist principles to gain life experience in understanding the universe for wisdom articulation; and (2) the commodification of false ritualistic and superstitious practices of Buddhism without understanding that the true meaning of Buddhism lies in the release of mental fixations to any type of physical or psychological ritual in order to achieve wisdom through understanding the universe at it is. However, ironically, while misinterpretation and the false practice of Buddhism can be harmful and make people even more ignorant, as well as attracting public controversy, this chaotic context can divert people's attention from the state's misconduct. This has further challenged managerial approaches in introducing practical and applicable Buddhist practices in organizations.

The following sections of the paper detail the specific application of Buddhist practices that informs distinctive managerial practices in response to trust issues in the context of Vietnam.

\section{Managerial Approaches}

In responding to contextual challenges related to a lack of trust, managers can either be cautious about adopting skillful approaches, or proactive in responding to issues of social trust. For instance, as stated by the CEO/Director of TUS: "Vietnamese business people work based on relationships and trust. They only work with those they already know well," indicating that this manager built relationships in ways consonant with social network theory. However, the majority of our respondents had found applying managerial approaches incorporating Buddhist principles helpful in perceiving trust issues as both challenging and rewarding. The following sections demonstrate how managers have incorporated Buddhist principles in their managerial practices to respond to social trust issues at the organizational level.

\section{Context-Sensitive Approach}

Senior executives spoke of the usefulness of a contextsensitive approach to repairing trust based on the Buddhist principle of impermanence. More than half of the respondents shared their understanding and application of the principle of impermanence-in both life and the workplace. By understanding that phenomena are impermanent, respondents felt more able to manage sensitively and flexibly in different contexts due to a higher level of emotional intelligence, which assisted them in enhancing relationships with employees. For instance, the CEO of a telecommunications company indicated that the ability for sense-making in a context-sensitive manner and based on the notion of impermanence can activate ethical codes of personal behavior. Other respondents reported variously that being contextually sensitive positively affected their flexibility in dealing with important partners or employees, prioritizing ethical conduct over financial pursuits, customizing products and services according to customers' preferences and tastes, and in welcoming recommendations and proposals from employees. According to the CEO of a pharmaceutical company, this context-sensitive approach is particularly significant in the Vietnamese pharmaceutical industry for the following reasons:

People complain about poor medical service, infrastructure and the availability of quality medical products and they have lost trust in the public health sector. We cannot change the policies of the Ministry of Health, however we are trying collectively, with support from some public and private hospitals, to deliver reliable and good pharmaceutical products to patients [...] We have a lot to consider in the pharmaceutical industry: the distinctive diseases of a tropical country, 
the living standards of the Vietnamese people, and the limited access to medications in rural areas. Being contextually sensitive is extremely important in doing business in our industry.

A context-sensitive managerial approach therefore fosters managers' acceptance of the impermanent nature of external phenomena by 'letting go' of their expectations of weak formal institutions such as the ineffective policies of the Vietnamese Ministry of Health. This viewpoint promotes proactive collective and personal ethical codes of compassion that consider the needs of the community, rather firms' financial interests. Such an approach helps managers to become more able to avoid subjectivity and the abstract generalizations that make them blind to context (Lowe et al. 2015) and alternative ways to respond to context. Sensitivity to context counters inactivity in managers based on expectations of improved formal institutions and helps them be open to alternative managerial practices in handling concerns over social trust issues. It fosters a proactive approach in responding to the impermanent nature of external conditions.

\section{Non-extreme Approach}

A non-extreme managerial approach was also promoted by senior executives in our study. This approach is based on the principle of the Middle Way in Buddhism.

Respondents reported that the moderate and balanced view advocated in the Middle Way had encouraged them to personally embrace ethical codes in practicing equality, fairness, tolerance, and transparency in their management. They practiced equality in listening and respecting subordinates' views, and showed fairness by taking responsibility for any collective mistakes. More importantly, respondents found solid justifications in the Middle Way for resisting the temptation to act in their own interests to the detriment of the common good, which is a challenging yet needed value in the contemporary Vietnamese context with its institutionalized corruption and associated lack of trust. Similar to how the Middle Way is applied by Buddhist economists, senior executives in our study used this principle to balance profit, sustainability, and non-coercive leadership. The CEO of a telecommunications company discussed how he used the Middle Way to focus on sustainable and ethical leadership, rather than seeking financial gain through illegal business practices based on the widespread practice of ignoring copyright issues in Vietnam:

In Vietnam, we have websites for online videos or movies. Previously I had the opportunity to become a pioneer in that area, creating websites for accessing premium quality video for watching movies. However, after realizing that it is not a sustainable business practice because of copyright issues, we stopped doing it.
Some other companies have become successful in this type of business, but they do not have copyright. I am aiming for long-term sustainability and not shortterm profits. In Vietnam, unauthorized and non-copyright businesses are common. I do not follow such an approach. That is wisdom. We should not let our greed overcome virtuous conduct [...] it also helps to send a clear message to our organizational members of the kind of ethical business we are doing regardless of common unethical practices in the market.

In summary, the non-extreme approach stimulates the practice of transparency through moderate and ethical leadership and actions. This approach is crucial in contexts like Vietnam, where weak legal institutions create opportunities for greed in business pursuits and there is a need to respond skillfully and ethically to contextual constraints. In the excerpt above, moderation facilitates the manager's morality in not exploiting the vulnerable status of copyright in Vietnam, as indicated in Cohen and Dienhart's (2013) moral conceptions. This moral character is enhanced by the ability to recognize the long-term 'suffering' that comes from the excessive desire to maximize short-term profit. The Middle Way approach helps managers to differentiate and moderate reflexively between individual materialistic pursuits for short-term gain and common unethical collectivist shielding practices that contribute to the promotion of collective corruption, which can lead to long-term suffering and endanger social trust. Our respondents also stressed that the exploitation of weak legal formal institutions by individuals who fail to manage their desires and moral character can result in serious unethical and karmic consequences that further deteriorate the already vulnerable social trust in the context of Vietnam.

\section{Skillful Approaches}

The managers had introduced and embraced the concept of 'skillful means' in their managerial practices. Skillful means (phương tiện thiện xảo) (Upāya Kausalya) was a distinct technique used by the Buddha to deliver his teachings to his followers, whereby he contextualized a variety of philosophical and religious ideas depending on his audience (Schroeder 2004). Skillful means is more about how something is taught rather than the content of the teaching, and is a way of responding to the unique karmic forms of human beings. In today's terms, skillful means indicates a contextualized rather than a universal approach in response to concerns over contemporary issues. No two people suffer in the same way and there are no general rules. Individuals with different backgrounds, and different beliefs and perceptions will consider different things as suffering. Therefore, as a technique and form of interpretation, skillful means 
is applicable to contemporary organizational workplaces, which require a high degree of flexibility and reflexivity at many levels.

As a Buddhist concept, skillful means has barely been referenced in scholarship, mainly because of its controversial nature and the lack of practical empirical data to back it up. Skillful means has occasionally been considered no more than the Buddha's trick to win over followers (Federman 2009a, b; Schroeder 2004, 2011). Our findings demonstrate the relevance of skillful means in managerial practices, particularly its efficacy in addressing trust issues in the context of Vietnam. A national manager of a manufacturing group described how a skillful means approach had helped him to better understand his employees' capabilities and weaknesses:

Incorporating Buddhist skillful means in my managerial role brings 'life value' to what I do. It is also an effective way of managing employees. For instance, I customize my management to specific individuals. With highly skilled and experienced employees, I give them freedom to work on their own. They can choose their own methods of accessing potential customers and build up their sales strategies. However, there are employees whom I need to coach individually and help step by step. I try to let them work out their problems on their own as a means of self-development. And there are also less confident employees. With employees with low self-efficacy, I have to show things in detail, even sharing my personal life experiences to encourage them. I admit that these approaches are time-consuming. However, on the positive side, you get to know your own people and they respect and trust you.

To facilitate positive interpersonal interaction and cooperation as suggested by Hosmer (2008), the above respondent demonstrated skillfulness in promoting codes of kindness and compassion to secure the trust of employees. Likewise, some respondents skillfully addressed concerns and skepticism toward the instrumentalization and commercialization of mindfulness programs in organizations (Purser and Loy 2013). These managers used a variety of initiatives to foster employee development-physically, psychologically, and more importantly, intellectually. This approach is similar to the knowledge, thinking, emotional, and motivational components of practical wisdom (Moberg 2007). However, it is important to highlight that while practical wisdom relies on these components, skillful means operates on the basis of non-attachment, which involves the practice of nonself in sacrificing personal values for other meaningful or demanding circumstances. For instance, a senior manager of a construction company shared that, sometimes, skillfulness means letting go of introducing mindfulness practices to the workplace if they are unsuited to the capabilities of employees or the nature of their work. It moves away from excessive attachment to one-size-fits-all managerial perspectives that have led to the commodification of mindfulness practices in contemporary organizations. This approach helps managers gain useful intelligence to balance interpersonal, intrapersonal, and extrapersonal interests, support well-adjusted responses to contextual challenges (Sternberg 1998), and get to know employees better by listening to them and respecting their needs. It also creates opportunities to explore the assumptions underlying employees' concerns over trust and find skillful solutions to address these concerns. Furthermore, based on social network theory, this approach fosters the participation of employees in informal networks that encourage the development of social trust (Delhey and Newton 2003). These empirical findings support calls for mindfulness training as ethical, long-term, and holistic practice (Qiu and Rooney 2017).

\section{Mindful Approach}

Respondents in our study showed signs of being both compassionate and rational in their managerial approaches. They tended to combine compassion (tì bi) (karuṇa) and wisdom (trí tuệ) (Sanskrit: prajñā; Pāli: pañ̃̃a) in managing complex or challenging situations. In organizational studies, compassion has been shown to ease painful and extreme experiences by influencing the perceptions and feelings of individuals (Cameron 1994; Gittell and Cameron 2003; Wanburg et al. 1999). Significantly, our respondents combined compassion and wisdom in a mindful approach to their managerial practice, highlighting the practicability of this approach in contemporary contexts. They described how the mindful approach had guided them away from the extreme positions of either being too compassionate without logical and analytical thinking, or being too rational and not contextually sensitive in responding to challenges or ethical dilemmas. It takes more than just compassion to gain employees' trust. A manager of a pharmaceutical company reaffirmed that compassion alone is not enough and sometimes can even be counterproductive in attending to social trust issues at the organizational level:

You need to be mindful in organizations. You cannot be compassionate toward consistent and intentional wrong-doing or unethical behaviors. I am willing to assist employees with family difficulties. I can review their personal case to assign appropriate tasks to them or even provide them some time off to solve their family issues. However, if someone intentionally sabotages the workplace, I will warn that individual the first time, but will dismiss that individual without hesitation if he or she continues 
to create a harmful working environment. In this way, you can present a practical and simple example for other employees to enhance a positive working environment.

According to respondents, attending to individual difference and needs in a mindful way at the organizational level fosters an ethical and inclusive culture. Our findings align with Simpson's (2014) view that compassion without wisdom is sentimentalism and wisdom without compassion leads to arrogance. In the context of Vietnam, it is essential to have both, especially in cases where managers have to deal with the contextual and relative meanings of ethics. Managers in the study indicated that the business context in Vietnam is full of ethical dilemmas (Robertson et al. 2002), with no clear moral right or wrong to guide decision-making. In such cases, having a strong moral character as a manager is crucial; however, such moral character needs to be negotiated in a mindful way against the context. The director of a pharmaceutical company presented an example to demonstrate this approach in practice:

There is no right or wrong way of dealing with bribery.

A skillful and mindful leader is the one who knows how to make a smart decision. In my opinion, if an act of bribery can bring benefits to patients, or introduce a valuable product that can help to increase people's health in the long term, I am willing to pay the transactional cost of bringing that product to patients - as long as the cost is acceptable and appropriate in the given context. For me, showing compassion in exchange for the personal sacrifice of accepting the need to engage in bribery is eventually a right doing.

Making the right moral decision is not always easy, as suggested by the above respondent. A sacrifice sometimes has to be made, in this case refers the sacrifice of personal moral ethical codes for the benefit of a greater community. Here, the Buddhist notion of 'letting go' applies even to excessive attachment to personal ideologies of what is right and wrong in a paradoxical situation, where the moral weight has to be negotiated against the relevance of context and outcome for a larger audience as compared the distress of one individual. As such, a mindful approach highlights that to facilitate social trust, a managerial decision has to be renegotiated frequently against given sets of particularities because the state of social trust is impermanent. Being mindful toward ethical considerations in ambiguous and complex contexts is important for managers because subordinates tend to pay attention to the ethical and character-focused aspects of managerial performance (Hogan et al. 1994). This approach requires skillfulness, just as practical wisdom fosters morally 'right' responses in 'right' contexts (Moberg 2007).

\section{Egoless Approach}

In attending to the low levels of trust within the Vietnamese context in general, and employee skepticism in particular, respondents had applied Buddhist concepts of non-self and emptiness to demonstrate an egoless approach. A number of papers have referred to the concept of 'non-self' in leadership practice (Kovács 2014; Kriger and Seng 2005; Swierczek and Jousse 2014), but not so much to emptiness. Both non-self and emptiness demonstrate the notion of nonattachment, representing a viewpoint that nothing exists forever and that a personal self with fixity is an illusion (Schuyler 2012). These concepts reject egocentric approaches to promoting compassion. The managers in this study felt that applying this egoless approach made them become less authoritarian in acknowledging the roles of employees. They consulted with employees in decision-making, which in turn enhanced positive leader-follower relationships that may lead to social trust according to the social network theory (Delhey and Newton 2003). A national manager of an interior design company revealed how the egoless approach can be effective, as below:

Leadership is not just about tasks, but also about the ability to understand and motivate employees. At work, we should listen to even the contradictory views and opinions of employees. In fact, if employees have opposing opinions and are critical of a project, product or service, it can be beneficial for the business. In many cases, criticisms raised in our staff meetings have led to great innovative ideas. Allowing room for employees to show their capabilities and critical thinking without imposing my own perceptions or ideas also increases employees' trust in my leadership.

More than half of the respondents also highlighted that taking an egoless managerial approach had involved a process of self-transformation and personal development in enhancing soft skills to understand and appreciate people around them, as well as understanding and recognizing their own inner selves and shortcomings. A director of the National Water Resolution Corporation shared his experiences of personal transformation and development as a leader through applying the concept of non-self in an egoless managerial approach:

I have learnt that as a leader you need three things to succeed in today's context, which all involve personal transformation and rejection of self-manipulated perceptions. They are - mind and heart (tâm); knowledge and wisdom (trí); and leadership influence. Forget about your 'self'. Your employees are not your possessions. Applying mind and heart to leadership means not abusing your power to make others do whatever 
you want. Being skillful in accessing and absorbing useful information is how you show your influence. And finally, you handle contextual challenges by demonstrating knowledge, skillfulness, and wisdom. These for me are the most important lessons I have learnt in my role as a leader.

Egoless managerial approaches generate supportive working environments and foster a less authoritarian management style that shapes positive relationships in the workplace. This approach therefore helps to minimize the skepticism of employees. The self-transformation involved in the process demonstrates a letting go of mental fixations on individual pursuits. This process cultivates personal ethical and moral codes of honesty and truthfulness by facilitating personal acknowledgment of shortcomings through a positive reflexive process.

\section{Exemplar Approach}

The exemplar managerial approach is another important and practical approach needed in managerial or leadership roles to tackle trust issues, according to our respondents. The exemplar approach is based on the Buddhist principle of dependent arising (duyên khơii). Setting an example as a manager or leader is one way of showing respect to followers. When managers demonstrate that they fully understand the tasks and responsibilities of employees and are willing to support them, this facilitates development of social trust in leader-follower relationships as confirmed by social network theory (Delhey and Newton 2003). For the respondents, leading by example had provided opportunities to understand the context employees were experiencing in their specific tasks, thus stimulating understanding and enhancing interpersonal relationships-an important source of social trust.

In particular, the exemplar managerial approach strengthens and stimulates employees' appreciation of managers when managers show themselves as role models, both ethically and professionally. A regional manager of a pharmaceutical company shared that:

Personally, I feel that in the context of Vietnam, actions speak more than words. People no longer just believe in what other people say. Also, because relationships and connections are very important in our culture, people talk about others and word-of-mouth is a powerful instrument in Vietnam. Therefore as a leader, it is important to be an example both ethically and professionally to earn employees' trust, or to guide them. For example, I always tell my subordinates that honesty is very important. I am being honest about our products with patients, outlining both their strengths and weaknesses so that patients can choose. When employees see my approach, they appreciate our company's vision.

The exemplar managerial approach can therefore have a significant impact on employees following the vision of the organization. As suggested by our respondents, it is also an effective tool to enhance interpersonal relationships by letting "actions speak first," with those in managerial roles acting as examples in showing appreciation of each individual's context and differences, and in recognizing the collective role of the organization in creating a positive and healthy working environment. This approach encourages the moral characteristic of honesty in managers to cultivate a positive ethical organizational culture. Through this approach, managers can effectively transform and work with employees to share wisdom in suitable contexts because organizations cannot become wise by having only a few wise individuals; rather the transfer of wisdom is needed to make wise organizations (Bierly et al. 2000).

\section{Sustainable Approach}

The majority of senior executives in our study were particularly keen on demonstrating a sustainable managerial approach in the interests of meaningful development for both the organization and individual leaders. The sustainable managerial approach was based on respondents' awareness of impermanence and, more importantly, the principle of karma. Karma (nghiẹp) is one of the basic principles of Buddhism. Karma means 'action.' It has two components: a present circumstance, determined by actions undertaken in a previous life; and future karma, determined by actions undertaken in the current lifetime (Davidson et al. 2005). Sogyal Rinpoche (1994) highlights that the results of actions may not ripen immediately, but no one can escape from the consequences of karma. Therefore, karma reflects a philosophy of predestination (Paranjpe 1984).

Awareness of karmic consequences encourages leaders to avoid 'stealing' from future generations (Schumacher 1973). This concept is particularly important in contemporary contexts since many businesses aim for speed, efficiency, and low cost ends that are far from sustainable. Karma shapes the assumptions underlying thought prior to the formation of actions and is badly needed in contemporary contexts filled with personal and organizational agendas that affect stakeholders' trust in the organization. A number of the respondents described the influence of this philosophy in raising their awareness of the need to change their company's vision and make improvements to their business. They were not happy with how their businesses focused more on financial security at the cost of sustainability, nor the "relationship-oriented" nature of the work that required "lobbying." A manager of a 
construction company questioned the nature of her job and was thinking about alternative ways to make it meaningful and sustainable:

I am not that satisfied with the job that I am doing right now. Because the more we build new houses, the more land we take. It also means that we take away the means for farmers to earn a living. If I had chosen a job that only brings benefit to people, I would like it more. However, there are still aspects of my job that I do like. We are trying to use sustainable materials, building quality houses and providing value-added services for sustainable maintenance, as well as residential services free of charge for our customers and residents. We have also built a yoga center available free of charge for our residents to help them enjoy the best quality of life $[\ldots]$ earning employees trust does not come easy. It comes with honesty and long-term ethical vision.

Karma is therefore an important notion that contributes to the generation of honesty and ethical vision in contemporary contexts, responding to Yang's (2011) call for more leadership that displays wisdom, not only for the benefit of the organization but for the well-being of wider society. While the Vietnamese people might think that corporate social responsibility and sustainability activities are a luxury in a developing country like Vietnam, there can be no long-term development without sustainability. The non-sustainable and short-term activity allowed by the weak formal institutions of the open-door policy introduced as part of the economic reforms in Vietnam has contributed to the low levels of trust within Vietnamese society due to the greedy pursuit of materialism.

The managers in the study had introduced some distinctive managerial approaches to repair trust, and in response to the growth of engaged Buddhism in the country. These approaches have been somewhat effective in enhancing interpersonal relationships among organizational members and responding to the complex contemporary context of Vietnam. However, a number of respondents had also encountered personal challenges because these practices do not just involve change in managerial techniques, but also a process of self-transformation and the ability to let go of some familiar managerial habits. The CEO of an education organization explained:

Transforming yourself in line with Buddhist practice is a long and challenging task. Our nature is greedy, selfish, lazy and fearful. It takes years of practice, experience and even failure to change a habit or a perception.

Expanding on this opinion, the above respondent highlighted that after 20 years of practicing Buddhism, he still sometimes found it challenging to tame himself. He made a very interesting comment on the nature of human ignorance that helps to explain why self-transformation takes time:

From birth we all have a similar and common denominator, which is ignorance. It is only the numerator or our level of ignorance that varies. Buddhism helps people to get out of illusions in life. We need to transform our troubled mind to a pure mind. The fundamental of it is wisdom.

He further expressed that wisdom articulation is a long and reflexive process to reduce our levels of ignorance and that this process can never be complete due to the impermanent nature of the context. Based on his experience, he found that even though Buddhist practice is a self-transformational process, it is always helpful to have a support group of other Buddhist practitioners (not necessarily sharing the same Buddhist practice or path) to share experiences of engaged Buddhism in life and to help with reflexivity because sometimes shortcomings are harder to acknowledge due to the different levels of maturity in practicing non-self.

In summary, all the above managerial approaches somewhat resemble Fukuyama (2000) and Hosmer's (2008) norms with regard to religion in promoting interpersonal interactions and cooperation that can facilitate social trust through personal ethical codes such as honesty, truthfulness, temperance, compassion, and kindness. As found in this study, the informal forces of spirituality and engaged Buddhism can positively impact social trust in interpersonal relationships and at an organizational level. In particular, approaches based on the notion of non-attachment in Buddhism consider the moral implications of taking advantage of the vulnerability of weak formal institutions for unethical gain and selfish pursuits. This study shows how religion as an informal institution can replace formal institutions in dealing with trust issues in emerging economies similar to Vietnam in terms of being a one-party or authoritarian state with institutionalized corruption and a collectivist culture.

On the other hand, this study has identified a range of managerial approaches based on Buddhist principles that can be considered skillful means, and which reflect the concept of practical wisdom (Aristotle's phronesis), especially in cultivating morally valued responses to moral dilemmas (Badaracco 1997). These managerial approaches contribute a non-Western view on how emerging economies find ways of dealing with trust issues in response to institutional rigidity and its weaknesses through developing ethical agency and bootstrapping the development of trust through skillful means. However, the managerial approaches our respondents expressed in response to the low trust context of Vietnam were not just about the tradeoffs between morally valued alternatives (Kidder 1995). They indicated a reflexive and transformational process of cultivating, adjusting, and even rejecting managerial practices in a context-sensitive 
manner. Through moderation, non-attachment, and mindfulness, managers are negotiating the impermanent nature of the challenges of social trust issues. These managerial skills and approaches are important not just for the context of our study, but for emerging contexts with similar trust issues.

While these managerial approaches have been derived from the specific context of Vietnam and the practice of engaged Buddhism in this country, they represent useful practice for creating ethical agency for contemporary managers in general. For instance, all of these approaches cultivate moral approaches for managers based on the notion of letting go of excessive forms of attachment in various ways: namely, letting go of excessive financial pursuits, egoistical desires, rigidity in defining ethics in paradoxical contexts, short-term pursuits resulting in karmic consequences, and even attachment to the overuse of compassion or empathy that may lead to favoritism or partisanship (Thompson 1975). Further, flexibility in adopting a variety of managerial approaches as skillful means emphasizes the need for practical wisdom, and social and cultural intelligence with regard to awareness of karmic consequences in considering sustainability and long-term orientations in managerial decisionmaking; non-attachment, non-self, and reflexivity in adopting a particular viewpoint and then having the courage and capability to abandon context-insensitive or egoistic managerial viewpoints or pursuits; impermanence as underlining context-sensitivity in management; and mindfulness of both the current situation and also past experiences of success or failure in evaluating and responding to ethical dilemmas or complex contemporary managerial issues. Importantly, these practices involve a parallel process of self- transformation in managers, especially in realizing their own shortcomings and abandoning impractical or context-insensitive managerial approaches.

\section{Conclusions and Avenues for Future Research}

The study has highlighted the role of spirituality and Buddhist principles in influencing managers' morality, reciprocity, and civic engagement based on the research question: "How does engaged Buddhism influence managerial approaches in the low trust context of Vietnam?" It makes both theoretical and practical contributions.

The findings of the study communicate an approach in response to trust deficit in a transitional context, demonstrating how spirituality and Buddhism can facilitate managers in attending to issues of social trust in the context of Vietnam. The study introduces a Buddhist perspective on trust and unpacks the fundamental causes of distrust-excessive desires and attachment- which in Buddhism lead to suffering. The notion of non-attachment is the foundation of the managerial approaches identified in our findings, as these approaches move away from numerous forms of excessive attachment to facilitate the development of moral characteristics in managers. In turn, these characteristics facilitate positive interpersonal relationships, which according to social network theory can cultivate the development of social trust (Delhey and Newton 2003). A context-sensitive managerial approach applying the Buddhist principle of impermanence fosters personal ethical codes of temperance and compassion; a non-extreme approach applying the Middle Way embraces the moral codes of equality, fairness, tolerance, and transparency; a skillful approach that applies skillful means promotes codes of kindness and compassion; a mindful approach combining wisdom and compassion encourages moral ethical codes that consider the benefits to the greater community; an egoless approach that practices non-self and emptiness cultivates the moral codes of honesty and truthfulness; an exemplar approach facilitates honesty and positive ethical organizational culture; and a sustainable approach that appreciates the notion of karma stimulates honesty and ethical vision.

These approaches are suitable for contexts suffering from moral degradation and trust issues such as Vietnam. The findings suggest that a skillful approach promotes skillful interpretation of the context to skillfully attend to ethical paradoxes of institutionalized bribery; an exemplar and egoless approach in management is crucial to nurturing authenticity to foster positive interpersonal relationships; and egoless and non-extreme approaches based on the concepts of emptiness and the Middle Way counter illusions about 'self' and so enhance individual reflexivity and context-sensitivity. Many trust-related issues are caused by dishonesty and moral degradation (Zheng et al. 2014) due to the pursuit of ends at any cost. Therefore, understanding moderation through applying the principles of the Middle Way (nonextreme approach) and karma (sustainable approach) is needed in contemporary management.

The findings of this study do not distinguish between these managerial approaches in terms of importance, but instead emphasize consideration of moral weight in rejecting the excessive pursuit of desires in any form that may result in the exploitation of weak formal institutions, unethical behavior, or karmic consequences. The study contributes a proactive and ethical approach to improving interpersonal relationships in response to issues of social trust. Active, mindful, and skillful engagement with contextual constraints is encouraged to facilitate understanding of the complex underlying causes of trust issues.

The study demonstrates how informal institutions can replace formal ones when formal institutions fail to promote social trust in society. We have broadened and extended the literature on institutions by incorporating informal rules into institutional analysis. According to Helmke and Levitsky 
(2004), it is challenging to specify informal institutions because they are normally "unwritten, created, communicated, and enforced outside of officially sanctioned channels" (p. 727). The value of our contribution therefore lies in recognizing specific informal institutions that relate to ethics and trust issues, namely, Buddhism and spirituality. We focus on the role of religion in promoting the moral aspects of managers, which subsequently fosters corporative behaviors. The Buddhist religion as a substitutive informal institution is in its early stages in Vietnam. As a phenomenon it is worthy of deeper research because Buddhist practices have the potential to create a harmonious society based on sustainable development (see also Du et al. 2014). Moreover, Buddhism can provide individuals with "inspiration and extensive, profound knowledge in dealing with complexities" (Du et al. 2014, p. 503).

In practice, Buddhist-enacted managerial approaches promote ethical context-sensitive approaches that can respond to trust issues in the context of Vietnam in particular, and in other similar contemporary contexts in general. For instance, by customizing mindfulness practices in organizations based on individual psychological and physical needs, managers show respect to individual differences rather than commoditizing one-size-fits-all mindfulness practices (Purser and Milillo 2015). Likewise, managers can be sensitive and mindful about introducing spirituality, or the degree to which they allow expressions of spirituality within organizations, by moderating their expectations and pursuits to avoid signs of manipulation, or instrumentalization, through spirituality (Lips-Wiersma et al. 2009).

Further, the findings of the study demonstrate managerial approaches in responding to the dilemmas and situational ethics of a transitional context. A skillful, non-extreme, and context-sensitive interpretation of bribery, for example, is needed in a transitional context. In high-context cultures like Vietnam, conforming to a concrete perception or definition of ethics does not necessarily lead to best practices. As Cameron (2006) argues, being kind or ethical has no fixed point and nor can it represent universalistic standards; and occasionally it can even be problematic. Our respondents had also struggled with ethical decisions concerning institutionalized bribery as a form of latent tension (Beech et al. 2012). They revealed that considering sacrifices in terms of accepting transitional bribery costs in exchange for sustainable long-term efforts in cultivating social well-being, for example, can be practical in some circumstances in the context of Vietnam. Furthermore, understanding karmic consequences is crucial to fostering collective efforts in encouraging sustainable approaches that may respond in the long term to concerns over lack of trust in Vietnamese society. Such an approach also responds to concerns over how transitional developing economies are neglecting sustainable practices for short-term ends (Tencati et al. 2008). This approach is timely and desirable, both in
Western contexts suffering from corporate scandals, managerial misconduct, and low levels of trust in business (Edelman 2012; Kaptein 2008), and in non-Western contexts to counter greed, unethical business practices, and corruption scandals (Choi and Aguilera 2009).

Finally, we highlight the importance of contextualizing research and contextualizing methods (Johns 2006). It would have been impossible for us to get access to data without the snowball technique, as relationships and connections are important in high-context cultures like Vietnam (Hall 1976). Furthermore, skepticism in the Vietnamese context makes people in general and respondents in particular cautious in everything they do or say. A personal reference from a trustworthy source is important to vouch for interviewers, as is asking for written consent from interviewees.

Our study is not without limitations. The findings are highly contextualized. The management approaches described are context-sensitive and not static, and therefore subject to change and customization alongside the transitional nature of the setting. We encourage longitudinal research to verify the outcomes from and development of Buddhist managerial approaches, and further explore other possible approaches to trust restoration in the context of Vietnam using different spiritual or non-spiritual samples. In particular, since folk traditions play an important role in the country, we recommend further studies exploring and examining the influence of folk traditions, specifically the adaptation of folk songs (ca dao tuc $n g \tilde{u}$ ) in managerial approaches as folk songs represent a long tradition of trust in the wisdom and teachings of ancestors. On the other hand, given the critical scholarly conversations on the instrumentalization of spiritual practices in organizations, it would be useful to explore and examine employees' perspectives on trust issues and management approaches.

Funding This study received no funding.

\section{Compliance with Ethical Standards}

Conflicts of interest The authors declare no conflicts of interest.

Ethical Approval All procedures performed in the study involving human participants were in accordance with the ethical standards of the institutional research committee, and with the 1964 Helsinki Declaration and its later amendments or comparable ethical standards.

Informed Consent Informed consent was obtained from all individual participants involved in the study.

Open Access This article is distributed under the terms of the Creative Commons Attribution 4.0 International License (http://creativeco mmons.org/licenses/by/4.0/), which permits unrestricted use, distribution, and reproduction in any medium, provided you give appropriate credit to the original author(s) and the source, provide a link to the Creative Commons license, and indicate if changes were made. 


\section{References}

ADB. (2017). Asian development outlook 2017. Update. Sustaining development through public-private partnership. https://www. adb.org/publications/asian-development-outlook-2017-update

Ansell, C. (2011). Pragmatist democracy: Evolutionary learning as public philosophy. New York, NY: Oxford University Press.

Bachmann, R., Gillespie, N., \& Priem, R. (2015). Repairing trust in organizations and institutions: Toward a conceptual framework. Organization Studies, 36(9), 1123-1142.

Badaracco, J. L., Jr. (1997). Defining moments: When managers must choose between right and right. Boston: Harvard Business School Press.

Barber, B. (1983). The logic and limits of trust. New Brunswick, NJ: Rutgers University Press.

Beech, N., Gilmore, C., Cochrane, E., \& Greig, G. (2012). Identity work as a response to tensions: A re-narration in opera rehearsals. Scandinavian Journal of Management, 28(1), 39-47.

Bennett, N., \& Lemoine, G. J. (2014). What a difference a word makes: Understanding threats to performance in a VUCA world. Business Horizons, 57(3), 311-317.

Berger, P., \& Luckmann, T. (1967). The social construction of reality: A treatise in the sociology of knowledge. New York: Anchor books.

Bierly, P., Kessler, E., \& Christensen, E. (2000). Organizational learning knowledge and wisdom. Journal of Organization Change, 13(6), 595-618.

Boal, K., \& Hooijberg, R. (2001). Strategic leadership research; Moving on. Leadership Quarterly, 11, 515-549.

Bond, M. H., \& King, A. Y. (1985). Coping with the threat of Westernization in Hong Kong. International Journal of Intercultural Relations, 9(4), 351-364.

Boytsun, A., Deloof, M., \& Matthyssens, P. (2011). Social norms, social cohesion, and corporate governance. Corporate Governance: An International Review, 19(1), 41-60.

Bowlby, J. (1969). Attachment and loss, vol. 1: Attachment. London: Pimlico.

Bryman, A. (Ed.). (2013). Doing research in organizations (RLE: Organizations). Routledge.

Bryman, A., \& Bell, E. (2003). Breaking down the quantitative/qualitative divide. Business Research Methods, 465-478.

Cameron, K. (2006). Good or not bad: Standards and ethics in managing change. Academy of Management Learning \& Education, 5(3), 317-323.

Cameron, K. S. (1994). Strategies for successful organizational downsizing. Human Resource Management, 33(2), 189-212.

Choi, S., \& Aguilera, R. V. (2009). Corporate social responsibility dynamics in South Korea and Japan: A comparative analysis. In C. A. Mallin (Ed.), Corporate social responsibility: A case study approach (pp. 123-147). Cheltenham: Elgar.

Claessens, S., Djankov, S., Fan, J. P. H., \& Lang, L. H. P. (2002). Disentangling the incentive and entrenchment effects of large shareholdings. Journal of Finance, LVII(6), 2741-2771.

Cohen, M. A., \& Dienhart, J. (2013). Moral and amoral conceptions of trust, with an application in organizational ethics. Journal of Business Ethics, 112(1), 1-13.

Combs, A., Burneko, G., Goerner, S., Brown, T., \& Guenther, H. (2002). The embodied mind: Cognitive science and human experience. Cybernetics \& Human Knowing, 9(2), 83-91.

Dalai Lama, X. I. V. (1999). Ethics for the new millennium. New York, NY: Putnam Publishing Group.

Daly, J., Kellehear, A., \& Gliksman, M. (1997). The public health researcher: A methodological approach. Melbourne: Oxford University Press.
Daniels, P. (2011). Buddhism and sustainable consumption. In L. Zsolnai (Ed.), Ethical principles and economic transformationA Buddhist approach (pp. 35-60). Dordrecht: Springer.

Daniels, J. P., \& von der Ruhr, M. (2010). Trust in others: Does religion matter? Review of Social Economy, 68(2), 163-186.

Davidson, J. R. T., Connor, K. M., \& Lee, L. C. (2005). Beliefs in karma and reincarnation among survivors of violent trauma. Social Psychiatry and Psychiatric Epidemiology, 40(2), 120-125.

Delhey, J., \& Newton, K. (2003). Who trusts?: The origins of social trust in seven societies. European Societies, 5(2), 93-137.

Denzin, N. K., \& Lincoln, Y. S. (1994). Handbook of qualitative research. Thousand Oaks, CA: Sage Publications.

Dickhardt, M. \& Lauser, A. (2016). Religion, place and modernity: spatial articulations. In Southeast Asia And East Asia. Social Sciences in Asia (Vol. 40). Boston: Brill.

Du, X., Jian, W., Zeng, Q., \& Du, Y. (2014). Corporate environmental responsibility in polluting industries: Does religion matter? Journal of Business Ethics, 124(3), 485-507.

Dutton, J. E., Workman, K. M., \& Hardin, A. E. (2014). Compassion at work. Annual Review of Organizational Psychology and Organizational Behavior, 1(1), 277-304.

Edelman. (2012). Executive summary: 2012 Edelman Trust Barometer. http://de.scribd.com/doc/121501475/Executive-Summary2012-Edelman-Trust-Barometer,

Estrin, S., \& Prevezer, M. (2011). The role of informal institutions in corporate governance: Brazil, Russia, India, and China compared. Asia Pacific Journal of Management, 28(1), 41-67.

Farrell, H., \& Knight, J. (2003). Trust, institutions, and institutional change: Industrial districts and the social capital hypothesis. Politics and Society, 31(4), 537-566.

Federman, A. (2009a). Literal means and hidden meanings: A new analysis of skillful means. Philosophy East and West, 59(2), $125-141$.

Federman, A. (2009b). Literal means and hidden meanings: A new analysis of skillful means. Philosophy East and West, 59(2), $125-141$.

Ferraro, F., Etzion, D., \& Gehman, J. (2015). Tackling grand challenges pragmatically: Robust action revisited. Organization Studies, 36(3), 363-390.

Fukuyama, F. (1995). Trust: The social virtues and the creation of prosperity (No. D10 301 c. 1/c. 2). Free Press Paperbacks.

Fukuyama, M. F. (2000). Social capital and civil society. International Monetary Fund.

Game, A. M. (2011). Leadership and attachment theory: Understanding interpersonal dynamics in leader-follower relations. In The SAGE handbook of leadership (pp. 326-337).

Gioia, D. A., Thomas, J. B., Clark, S. M., \& Chittipeddi, K. (1994). Symbolism and strategic change in academia: The dynamics of sensemaking and influence. Organization Science, 5(3), 363-383.

Gittell, J. H., \& Cameron, K. S. (2003). Virtuous leadership, relationships, and forgiveness: The role of relational and financial reserves in responding to crisis. Unpublished doctoral dissertation, Brandeis University, Massachusetts, USA.

Glaser, B., \& Strauss, A. (1967). The discovery of grounded theory. London: Weidenfield and Nicolson.

Gotsis, G., \& Grimani, K. (2017). The role of spiritual leadership in fostering inclusive workplaces. Personnel Review, 46(5), 908-935.

Gray, C. W. (1997). Reforming legal systems in developing and transition economies. Finance and Development, 94(3), 14.

Gross, N. (2009). A pragmatist theory of social mechanisms. American Sociological Review, 74, 358-379.

Gunasekara, V. (1982). Basic Buddhism: An outline of the Buddha's teaching. Brisbane, QLD: Buddhist Society of Queensland. 
Hall, E. T. (1976). Beyond culture. New York: Anchor Press.

Helmke, G., \& Levitsky, S. (2004). Informal institutions and comparative politics: A research agenda. Perspectives on Politics, 2(04), 725.

Ho, D. Y. (1995). Selfhood and identity in Confucianism, Taoism, Buddhism, and Hinduism: Contrasts with the West. Journal for the Theory of Social Behaviour, 25(2), 115-139.

Hogan, R., Curphy, G. J., \& Hogan, J. (1994). What we know about leadership: Effectiveness and personality. American Psychologist, 49, 493-504.

Holstein, J. A., \& Gubrium, J. F. (1997). Active interviewing. In D. Silverman (Ed.), Qualitative research: Theory, method and practice (pp. 113-129). London: Sage.

Hooijberg, R., \& Schneider, M. (2001). Behavioral complexity and social intelligence: How executive leaders use stakeholders to form a systems perspective. In S. Zaccaro \& R. J. Klimoski (Eds.), The nature of organizational leadership: Understanding the performance imperatives confronting today's leaders (pp. 104-131). San Francisco, CA: Jossey Bass.

Horak, S., \& Klein, A. (2016). Persistence of informal social networks in East Asia: Evidence from South Korea. Asia Pacific Journal of Management, 33(3), 673-694.

Hoskisson, R. E., Eden, L., Lau, C. M., \& Wright, M. (2000). Strategy in emerging economies. Academy of Management Journal, 43(3), 249-267.

Hosmer, L. T. (2008). The ethics of management. New York: McGraw-Hill

Huff, L., \& Kelley, L. (2005). Is collectivism a liability? The impact of culture on organizational trust and customer orientation: a seven-nation study. Journal of business research, 58(1), 96-102.

James, S. P. (2004). Zen Buddhism and environmental ethics. Hampshire United Kindom: Ashgate.

Johns, G. (2006). The essential impact of context on organizational behavior. Academy of Management Review, 31(2), 385-408.

Jones, T. M., \& Bowie, N. E. (1998). Moral hazards on the road to the "virtual" corporation. Business Ethics Quarterly, 8(2), 273-292.

Jones, C., \& Spicer, A. (2005). The sublime object of entrepreneurship. Human Relations, 12(2), 223-246.

Kaptein, M. (2008). Developing a measure of unethical behavior in the workplace: A stakeholder perspective. Journal of Management, 34(5), 978-1008.

Khantipalo, B. (1992). Buddhism explained. Bankok: Silkworm Books.

Kidder, R. M. (1995). How good people make tough choices. New York: Morrow.

Kovács, G. (2014). Buddhist Approach to Sustainability and Achieving Millennium Development Goals. Buddhism for Sustainable Development and Social Change (pp. 113-127). Ho Chi Minh City: Religion Press

Kramer, R. M., \& Lewicki, R. J. (2010). Repairing and enhancing trust: Approaches to reducing organizational trust deficits. Academy of Management Annals, 4(1), 245-277.

Kraut, R. (Ed.). (2006). The Blackwell guide to Aristotle's Nichomachean ethics. Oxford: Blackwell.

Kriger, M., \& Seng, Y. (2005). Leadership with inner meaning: A contingency theory of leadership based on worldviews of five religions. The Leadership Quarterly, 16(5), 771-806.

Lama, D. (1995). The path to enlightenment. Ithaca, NY: Snow Lion.

La Porta, R., Lopez-De-Silanes, F., \& Shleifer, A. (1999). Corporate ownership around the world. The Journal of Finance, 54(2), 471-517.

Lee, D. Y., \& Dawes, P. L. (2005). Guanxi, trust, and long-term orientation in Chinese business markets. Journal of international marketing, 13(2), 28-56.
Lewis, J. D., \& Weigert, A. (1985). Trust as a social reality. Social Forces, 63, 967-985.

Li, P. P. (2009). The duality of crony corruption in economic transition: Toward an integrated framework. Journal of Business Ethics, 85(1), 41-55.

Lincoln, Y. S., \& Guba, E. G. (1985). Naturalistic inquiry. CA: Sage Publications.

Lips-Wiersma, M., Lund Dean, K., \& Fornaciari, C. J. (2009). Theorizing the dark side of the workplace spirituality movement. Journal of Management Inquiry, 18(4), 288-300.

Lowe, R., Pow, N., Serban, I., \& Pineau, J. (2015). The ubuntu dialogue corpus: A large dataset for research in unstructured multi-turn dialogue systems. arXiv preprint arXiv:1506.08909.

Luthans, F., \& Youssef, C. M. (2007). Emerging positive organizational behavior. Journal of Management, 33(3), 321-349.

Martin, K. D., Cullen, J. B., Johnson, J. L., \& Parboteeah, K. P. (2007). Deciding to bribe: A cross-level analysis of firm and home country influences on bribery activity. Academy of Management Journal, 50(6), 1401-1422.

Mayer, R. C., Davis, J. H., \& Schoorman, F. D. (1995). An integrative model of organizational trust. Academy of Management Review, 20, 709-734.

McGuire, M. B. (2002). Reigion: the social context. Long Grove: Waveland Press Inc.

McKenna, B., Rooney, D., \& Boal, K. B. (2009). Wisdom principles as a meta-theoretical basis for evaluating leadership. The Leadership Quarterly, 20(2), 177-190.

Midgley, G., \& Shen, C. Y. (2007). Toward a Buddhist systems methodology 2: An exploratory, questioning approach. Systemic Practice and Action Research, 20, 195-210.

Mikulincer, M., \& Shaver, P. R. (2007). Attachment in adulthood: Structure, dynamics, and change. New York, NY: Guilford Press.

Moberg, D. J. (2007). Practical wisdom and business ethics: Presidential address to the society for business. Business Ethics Quarterly, 17(3), 535-561.

Murti, T. (1955). The central philosophy of buddhism. London: Routledge.

Nelson, J. M. (2009). Psychology, religion, and spirituality. New York: Springer.

Nguyen, T. M. N. (2009). Social activities of Vietnamese Buddhism in relation to charity. Religious Studies Review, 3(1\&2), 47-63.

Nguyen, T. V., Weinstein, M., \& Meyer, A. D. (2005). Development of trust: A study of interfirm relationships in Vietnam. Asia Pacific Journal of Management, 22(3), 211-235.

Nielsen, R. P., \& Massa, F. G. (2013). Reintegrating ethics and institutional theories. Journal of Business Ethics, 115(1), 135-147.

Nishii, L. H., \& Rich, R. E. (2014). Creating inclusive climates in diverse organizations. In Diversity at work: The practice of inclusion (pp. 330-363). San Franscico: Jossey-Bass.

Niwano, N. (1980). Buddhism for today. New York: Weatherhill.

North, D. C. (1987). Institutions, transaction costs and economic growth. Economic Inquiry, 25(3), 419-429.

North, C. D. (1990). Institutions, institutional change and economic change. Cambridge: Cambridge University Press.

Nyanaponika, T. (1986). The vision of Dhamma. York Beach, ME: Samuel Weiser.

Offe, C. (1999). How can we trust our fellow citizens? Democracy and trust, 52, 42-87.

Organ, T. W. (1954). The silence of the Buddha. Philosophy East and West, 4(2), 125-140.

Painter, M. (2006). The politics of state sector reforms in Vietnam: Contested agendas and uncertain trajectories. In K. Hewison \& R. Robison (Eds.), East Asia and the Trials of neo-libralism (pp. 65-87). Taylor \& francis: Routledge.

Paranjpe, A. C. (1984). Theoretical psychology: The meeting of east and west. New York: Plenum. 
Peng, M. W. (2002). Towards an institution-based view of business strategy. Asia Pacific Journal of Management, 19(2), 251-267.

Pope, C., Ziebland, S., \& Mays, N. (2006). Analysing qualitative data. In C. Pope \& N. Mays (Eds.), Qualitative research in health care (3rd ed., pp. 63-81). Oxford: Blackwell Publishing.

Porter, J. (1994). The recovery of virtue. London: SPCK.

Purser, R. E. (2012). Deconstructing lack: A Buddhist perspective on egocentric organizations. Tamara Journal of Critical Organisation Inquiry, 10(4), 17.

Purser, R., \& Loy, D. (2013). Beyond McMindfulness. Huffington Post, 1(7), 13.

Purser, R. E., \& Milillo, J. (2015). Mindfulness revisited: A Buddhist-based conceptualization. Journal of Management Inquiry, 24(1), 3-24.

Putnam, R. (2001). Social capital: Measurement and consequences. Canadian Journal of Policy Research, 2(1), 41-51.

Qiu, J. X., \& Rooney, D. (2017). Addressing unintended ethical challenges of workplace mindfulness: A four-stage mindfulness development model. Journal of Business Ethics. https://doi. org/10.1007/s10551-017-3693-1.

Quang, T. (1997). Sustainable economic growth and human resources development in Vietnam. Transitions, 38(1-2), 257-280.

Raelin, J. A. (2016). Imagine there are no leaders: Reframing leadership as collaborative agency. Leadership, 12(2), 131-158.

Rāhula, W. (1974). What the Buddha taught (Vol. 641). New York: Grove Press.

Raiser, M. (2003). Trust in transition. In F. Bonker, K. Muller, \& A. Pickel (Eds.), Postcommunist transformation and the social sciences: Cross-disciplinary approaches. Lanham: Rowman $\&$ Littlefield.

Ralston, D. A., Egri, C. P., Stewart, S., Terpstra, R. H., \& Kaicheng, Y. (1999). Doing business in the 21 st century with the new generation of Chinese managers: A study of generational shifts in work values in China. Journal of International Business Studies, 30(2), 415-427.

Rinpoche, S. (1994). The Tibetan book of living and dying. San Francisco: Harper.

Robertson, C. J., Crittenden, W. F., Brady, M. K., \& Hoffman, J. J. (2002). Situational ethics across borders: A multicultural examination. Journal of Business Ethics, 38(4), 327-338.

Robinson, S. L. (1996). Trust and breach of the psychological contract. Administrative Science Quarterly, 41, 574-599.

Rothstein, B., \& Stolle, D. (2001, September). Social capital and street-level bureaucracy: An institutional theory of generalized trust. In ESF conference social capital: Interdisciplinary perspectives, Exeter, UK September 15-20.

Rousseau, D. M., Sitkin, S. B., Burt, R. S., \& Camerer, C. (1998). Not so different after all: A cross-discipline view of trust. Academy of Management Review, 23(3), 393-404.

Sahdra, B. K., Shaver, P. R., \& Brown, K. W. (2010). A scale to measure nonattachment: A Buddhist complement to Western research on attachment and adaptive functioning. Journal of Personality Assessment, 92(2), 116-127.

Sauerwald, S., \& Peng, M. W. (2013). Informal institutions, shareholder coalitions, and principal-principal conflicts. Asia Pacific Journal of Management, 30(3), 853-870.

Schreier, M. (2012). Qualitative content analysis in practice. London, UK: SAGE Publications.

Schroeder, J. W. (2004). Skillful means: The heart of Buddhist compassion (Vol. 54). New Delhi: Motilal Banarsidass Publication.

Schroeder, J. (2011). Truth, deception, and skillful means in the Lotus Sūtra. Asian Philosophy, 21(1), 35-52.

Schumacher, E. F. (1973). Small is beautiful. London: Abacus.

Schuyler, K. G. (Ed.). (2012). Inner peace-Global impact: Tibetan Buddhism, leadership and work. North Carolina: Information Age Publishing.
Scott, R. W. (2014). Institutions and organizations ideas, interests, and identities (Vol. Fourth). Thousand Oaks: SAGE Publications Inc.

Shen, C. Y., \& Midgley, G. (2007). Toward a buddhist systems methodology 1: Comparisons between buddhism and systems theory. Systemic Practice and Action Research, 20(3), 167-194.

Silverman, D. (2011). Qualitative research: Issues of theory, method and practice. Thousand Oaks, CA: Sage.

Simpson, A. V. (2014). Augmenting the limitations of organizational compassion with wisdom and power: Insights from Bhutan. Paper presented at ANZAM conference, Sydney, Australia, December.

Sosik, J. J., Gentry, W. A., \& Chun, J. U. (2012). The value of virtue in the upper echelons: A multisource examination of executive character strengths and performance. The Leadership Quarterly, 23(3), 367-382.

Soucy, A. (2012). The Buddha side: Gender, power, and buddhist practice in Vietnam. Honolulu: University of Hawai'i Press.

Soule, E. (1998). Trust and managerial responsibility. Business Ethics Quarterly, 8(2), 249-272.

Spiro, M. E. (1966). Religion: Problems of definition and explanation. In M. Banton (Ed.), Anthropological approaches to the study of religion. Taylor \& francis: Routledge.

Sternberg, R. J. (1998). A balance theory of wisdom. Review of General Psychology, 2(4), 347-365.

Steyrer, J. (2002). Stigma and charisma and the narcissistic personality. In B. J. Avolio \& F. J. Yammarino (Eds.), Transformational and vharismatic leadership: The road ahead (pp. 231-254). New York: JAI Press.

Swierczek, F. W., \& Jousse, D. (2014). Adam Smith as Bodhisattva? A metta analysis of global leadership. Journal of Management Development, 33(8-9), 786-796.

Tencati, A., Russo, A., \& Quaglia, V. (2008). Unintended consequences of CSR: Protectionism and collateral damage in global supply chains: The case of Vietnam. Corporate Governance, 8(4), $518-531$.

Tesch, R. (1990). Qualitative research: Analysis types and software tools. New York: Falmer.

Thich, N. H. (1998). Interbeing: Fourteen guidelines for engaged Buddhism. Berkeley: Parallax Press.

Thich, N. H. (1999). The heart of the Buddha's teaching: Transforming suffering into peace, joy and liberation. New York, NY: Broadway Books.

Thompson, V. A. (1975). Without sympathy or enthusiasm: The problem of administrative compassion. Alabama: University of Alabama Press.

Tideman, S. G. (2016). Gross national happiness: lessons for sustainability leadership. South Asian Journal of Global Business Research, 5(2), 190-213.

Transparency International. (2016). Corruption perceptions index 2016. Retrieved from https://www.transparency.org/news/featu re/corruption_perceptions_index_2016

Tykocinski, O. E., \& Pittman, T. S. (1998). The consequences of doing nothing: Inaction inertia as avoidance of anticipated counterfactual regret. Journal of Personality and Social Psychology, 75(3), 607.

Ulin, P. R., Robinson, E. T., \& Tollyey, E. E. (2004). Qualitative methods in public health: A field guide for applied research. San Francisco, CA: Jossey-Bass.

Uslaner, E. M. (1999). Democracy and social capital. In Democracy and trust (pp. 121-150).

Van Den Muyzenberg, L. (2014). The contribution of Buddhist wisdom to management development. Journal of Management Development, 33(8/9), 741-750.

Van Gordon, W., Shonin, E., \& Griffiths, M. D. (2016). Are contemporary mindfulness-based interventions unethical? British Journal of General Practice, 66(643), 94. 
Vu, H., Tran, T. Q., Van Nguyen, T., \& Lim, S. (2018). Corruption, types of corruption and firm financial performance: New evidence from a transitional economy. Journal of Business Ethics, 148(4), 847-858.

Wallace, B. A. (2005). Genuine happiness: Meditation as the path to fulfillment. New York, NY: Wiley.

Wanburg, C. R., Bunce, L. W., \& Gavin, M. B. (1999). Perceived fairness of layoffs among individuals who have been laid off: A longitudinal study. Personnel Psychology, 52(1), 59-84.

Welch, M., Sikkink, D., Sartain, E., \& Bond, C. (2004). Trust in god and trust in man: The ambivalent role of religion in shaping dimensions of social trust. Journal for the Scientific Study of Religion, 43(3), 317-343.

Wicks, A. C., Berman, S. L., \& Jones, T. M. (1999). The structure of optimal trust: Moral and strategic implications. Academy of Management, 24(1), 99-116.
Williamson, C. R., \& Kerekes, C. B. (2011). Securing private property: Formal versus informal institutions. The Journal of Law and Economics, 54(3), 537-572.

Yang, S. Y. (2011). Wisdom displayed through leadership: Exploring leadership-related wisdom. The Leadership Quarterly, 22(4), 616-632.

Zheng, Q., Luo, Y., \& Wang, S. L. (2014). Moral degradation, business ethics, and corporate social responsibility in a transitional economy. Journal of Business Ethics, 120(3), 405-421.

Publisher's Note Springer Nature remains neutral with regard to jurisdictional claims in published maps and institutional affiliations. 